\title{
COMICS' RECEPTION AS LITERATURE AND THE SUBJUGATION OF THE IMAGE
}

\author{
by \\ Michael Seravalle, B. A., Honours, English, B. Ed. \\ Toronto, Ontario, Canada
}

August 31, 2018

\begin{abstract}
A Major Research Project
presented to Ryerson University in

partial fulfillment of the

requirements for the degree of

Master of Arts

in the English MA Program

in Literatures of Modernity
\end{abstract}

Toronto, Ontario, Canada, 2018

(c)Michael Seravalle 2018 


\section{AUTHOR'S DECLARATION FOR ELECTRONIC SUBMISSION OF A MAJOR RESEARCH PROJECT}

I hereby declare that I am the sole author of this MRP. This is a true copy of the MRP, including any required final revisions.

I authorize Ryerson University to lend this MRP to other institutions or individuals for the purpose of scholarly research.

I further authorize Ryerson University to reproduce this MRP by photocopying or by other means, in total or in part, at the request of other institutions or individuals for the purpose of scholarly research.

I understand that my MRP may be made electronically available to the public. 
Seravalle 3
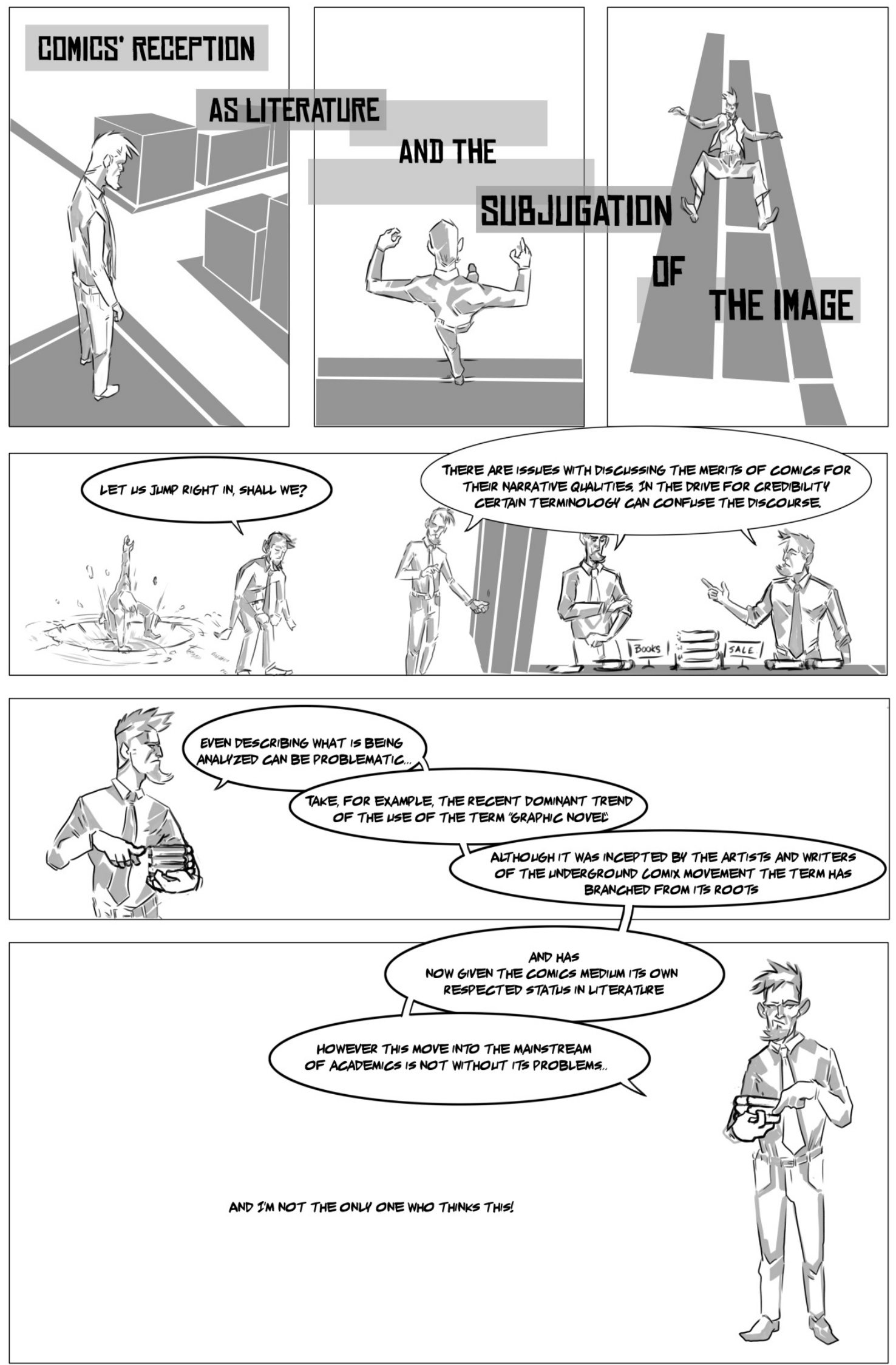

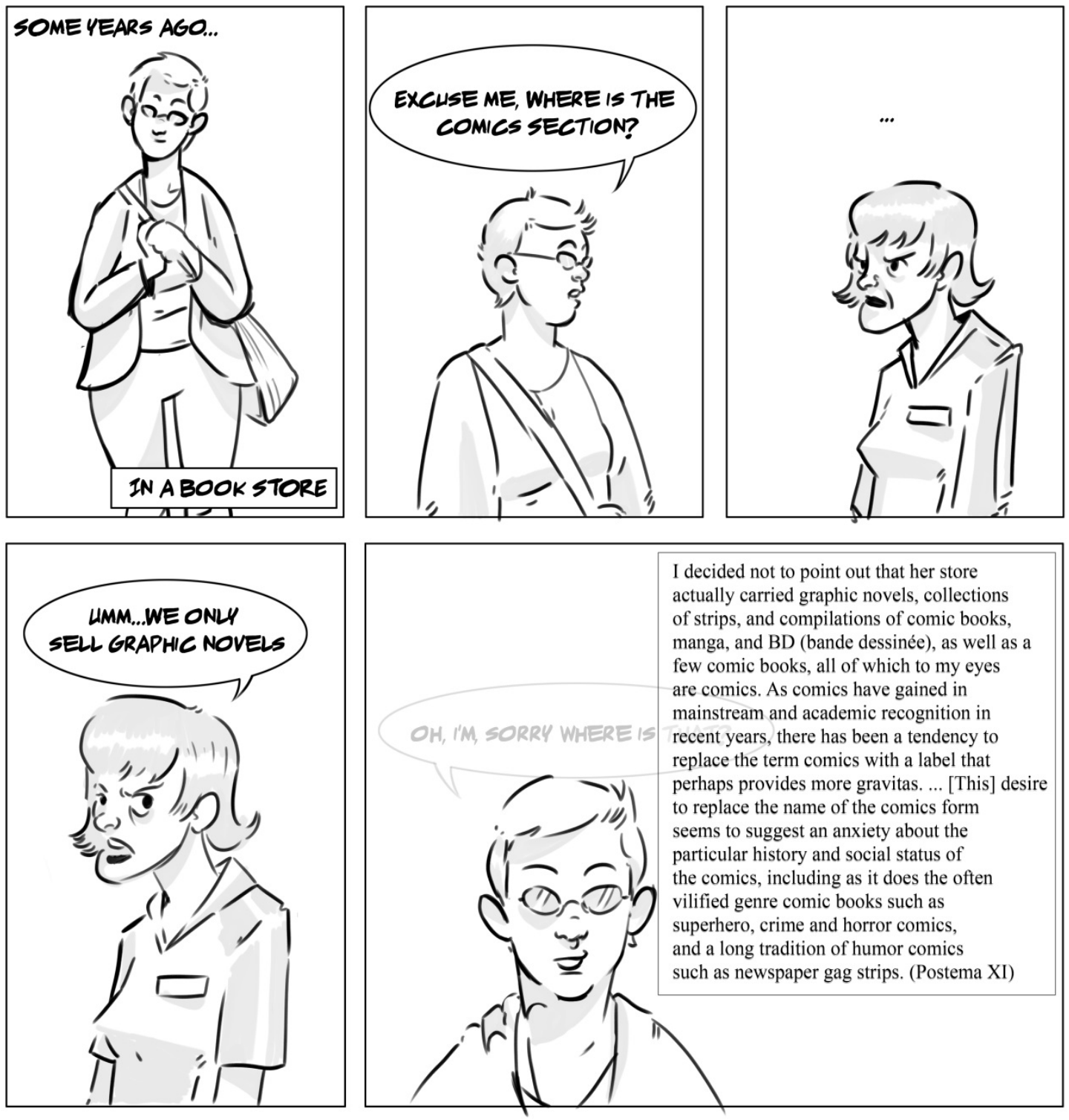

"... there is a danger inherent precisely in creating a separation and dissociation between different kinds of comics genres, especially when the labels are ill-defined or haphazardly applied, as with the usage of the term graphic novels in bookstores.

The scope of what the comics form can represent or incorporate becomes limited, diminishing the form itself, at least for casual observers, and the graphic novel or narrative becomes a genre without precedent or tradition, as if it originated all of a sudden in a vacuum, thereby misrepresenting the genre." (Postema XI).

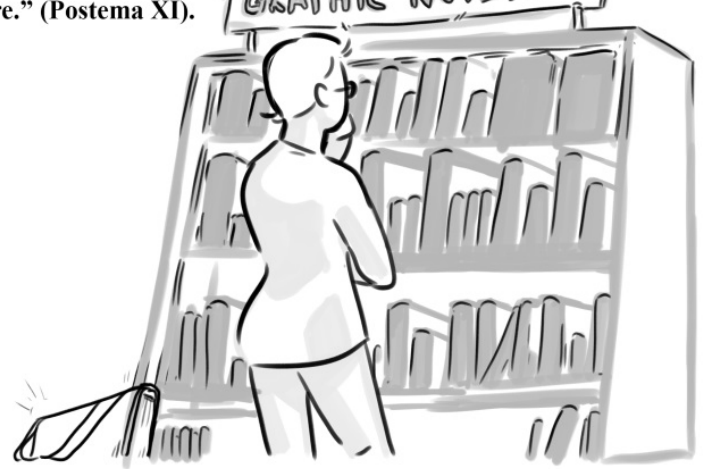


Scholars disagree on how comics should be defined in relation to other media. Some, such as Barbara Postema, assert that comics are representative of a medium featuring unique formatting and iconography that sits outside the traditional considerations of art and literature. The counter-point, as proposed by individuals such as Thierry Groensteen, is that comics are a hybrid or mixed medium, representing the combination of the written word and fine art working in conjunction to convey different perspectives within a single narrative. Historically, comics have been rejected by both fine art and literary communities due to their failure to conform to the standards presented in either discipline. However, due in large part to the narrative elements of the prose present in a comic text, comics settled primarily in the domain of literary consideration, albeit with some negative critique initially directed at the content and marketing that popularized the medium. Once considered rudimentary writing supported by gimmicky illustrations, the ongoing discourse concerning their status as either a unique medium or hybrid media has coincided with comics gaining academic merit in recent years. One of the issues that complicates this debate is whether the text and image in comics to be given equal consideration when determining the function of a comic narrative, as "one of the significant consequences of the literary turn in the study of comics has been the tendency to drive attention away from comics as a form of visual culture” (Beaty, Comics vs. Art 18). Compounding this tendency is the suggestion that narrative is exclusive to the domain of literary prose. Comics’ inclusion of sequential art challenges literary tradition through the levels of signification applied to formatting, such as "the image, the layout, the sequence, word-image combination, and finally narrative” (Postema 105). Historically, the use of image in comics has been condemned for lowering the literary quality of the narrative through claims made by critics such as Fredric Wertham that will be explored at length throughout this paper. The assertion that image in 
comics had no narrative value was compiled with the art actively rejected by the "fine" art community as failing to attain the level of "high" art. This has led to the devaluing of the image and its influence on narrative in comics, as "comic[s], [as] many critics will tell you, are not art" (Beaty, Comics vs. Art 18). Instead, comics have stood in opposition to art: "largely ignored by critics and art historians, and consequently disdainful of the interests of those groups, comics have long revelled in their lowbrow, badboy image” (Beaty, Comics vs. Art 19). Without the support of the artistic community to help establish a standard of critical approach, the comics industry evolved to place more emphasis on the literary element, as seen in the rise of the 'graphic novel' as a legitimating label for rebranding of the medium. Although scholars and critics such as Barbara Postema, Bart Beaty, and Scott McCloud recognize the importance of the image when critiquing narrative, the tendency to emphasize the writer over the artist as primary contributor of narrative value to a comics work has put the image and text of comics in separate categories, causing one to rise at the expense of the other.

The ascension of comics in academic discourse was due in large part to the resurgence of the industry in the 1980s and 1990s:

The principal factors that contributed to this situation were the evolution of the readership, the adaptation by the industry to the multiplication of specialized bookstores, and the increasingly important role given to creators $<\ldots>$ the 1980 s were characterized by a desire by publishers to maximize their revenues into two distribution systems. (Gabilliet 86-87)

The "graphic novel", "which was the industry term for books that offered new stories in the style of the European album” (Gabilliet 87), was the industry's attempt to distance comics from their illegitimate history, a rhetorical shift which will be discussed in greater detail later, by borrowing 
the credibility that novels have achieved as a form of literature. Yet the widespread use of this term represents a major issue in comics discourse, as it is indicative of a continuing disregard for the image as a core and equal element in the interpretation of a comic narrative. Although the term "graphic novel” has garnered academic respect for the medium, both in current and historic discourse, it favours the author over the artist in establishing the quality of the narrative, as in the case of the Revisionist writers of the 1980s and 1990s, which will be explored at length later on. The title "graphic novel” itself subjugates the image to an adjectival role when describing the medium, thereby altering its perceived merits. This theoretical framework serves to split readings of the medium into two clear sections: the image, and the text. The reader is thereby offered a two-track narrative with considerable experiential redundancy; they may choose to experience the narrative primarily through illustration or through text, leading to readings that favour comparison over comprehension. When approached in this manner, the image is little more than a supplement that accompanies the narrative text. By this logic, comics can neither be a hybrid medium, since image and text are not equal and interactive, nor its own unique medium, since it is functionally an illustrated novel. The subjugation of the image, therefore, weakens discourse regarding the merits of the medium as a whole.

The subjugation of the image in comics has been at the center of the discourse about the medium since its fall from grace during the 1940s and 50s, and throughout subsequent struggles with legitimacy. The term “comics” in reference to literature has often had pejorative connotations, and it is important to understand how historical associations shaped the medium's development and circulation, as well as its terminology. For this paper, the term "comics” will refer to the "medium” generally, with its own perceived rules and designations. To clarify 
further, the "comics medium" includes both solo or sequentially panelled images with the common addition of dialogue in order to convey a narrative or plot.
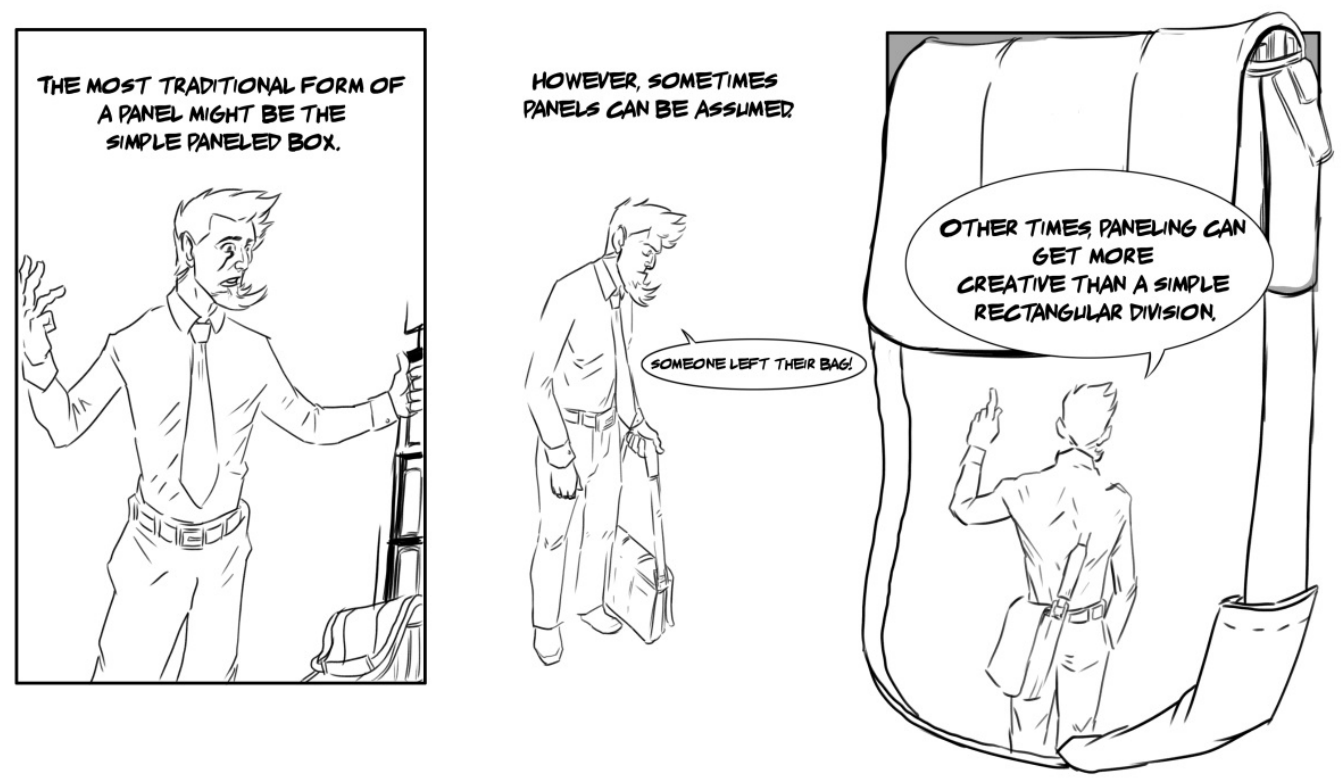

This definition includes and is not limited to designations such as "graphic novels," "manga," and some "picture books" (such as In the Night Kitchen by Maurice Sendak), which all attempt to convey narrative through the utilization of sequential images in combination with text. It is important to indicate, however, that this paper will explore how comics function as narratives and that simply including images does not grant a piece the status of a functional comics narrative. Although "picture books" can sometimes be considered a form of comics, the traditional format of a picture book does not meet the criteria of a functional example of the medium due to the way in which image and text are used in order to convey narrative. In his article "Picture Book Guy Looks at Comics: Structural Differences in Two Kinds of Visual Narrative” Perry Nodelman explores how comics function in comparison to picture books and how the two differ in their use of image and text in collaboration, stressing that: "in terms of structure, comics are more complicated than picture books" (437). Nodelman indicates that the 
images within picture books are acting in a supportive role, or as suggested earlier, are subjugated by the text:

Picture books seem to represent most centrally and more clearly the conventions of illustration: pictures as ways of offering further insight into what texts are saying (and, of course, the opposite). Comics, which offer more complicated combinations of back-andforth between text and picture, picture and picture, and text and text, on each page and spread as well as throughout a whole story, seem less centrally or purely illustrative. They offer a more complex relationship, one that seems to compromise or even thwart the basic principle of illustration by offering so many ways of thinking about what might be illustrating what. (Nodelman 438)

The emphasis on the image conveying an equal or greater value to the narrative is to ensure a separation of works that utilize image mainly as a form of illustration or as a visual embellishment for the text, such as frontispieces and figures. This separation is necessary due to an existing criticism of whether image is capable of carrying narrative on its own. In his book Comics and Narration Thierry Groensteen stipulates that the comics narrative "combines text and image in varying proportions. It is essential to start with the assumption that both play a full part in the narrative process" (83). The image in a comic narrative is not something that can be ignored as simply an illustration of what is being described by the text on the page, whether it be word bubbles or narration boxes, as "a substantial part of the narration is carried by the images, both within them and through their articulation on different levels” (Groensteen 83). In assuming that the image represents an illustration for the written word the reader ignores that there are multiple narratological perspectives within the comic. As Groensteen explains, "there is undoubtedly a dissociation between the told (with words) and the shown (by drawings), but the 
shown is itself a told. I had, moreover, defined comic art as a predominantly visual narrative form [within the "narrative genre"]" (Groensteen 83). Before exploring the narratological effects of image and text on the interpretation of a comics narrative, it is first important to discuss why, in their critical reception, comics were accepted within neither literary nor fine art discourses.

Even deciding what constitutes a comics narrative has been a historical point of contention due to the stigma placed on both form and content of the medium. In the chapter "The Impossible Definition” of The System of Comics, Groensteen indicates that theorists who try to define what art-forms constitute a comic are often limited in their scope; he condemns the proto comics theories, such as those of David Kunzle and Bill Blackbeard, presenting them as "equally normative and self interested, each made to measure in order to support an arbitrary slice of history” (Groensteen 125). This need to designate or clearly define comics as being represented by core formats can force particular lenses of critical theory that create exception due to exclusivity. By extension, in their attempt to be acknowledged as a legitimate form of media, comics are held to a standard of literary quality even though they are not strictly a literary medium. This focus on literary quality is part of the issue with identifying the role of the image in the medium insofar as the terminology needed to define it is dependent on existing language and expertise represented in multiple disciplines. As Miodrag indicates:

It is indisputable that words and images interact in producing comics' narratives; however, problems frequently arise when critics attempt to pin down the precise nature of this interaction. Critics often seize upon particular ways of combining image and text as being definitive of the form, though these definitions tend to account for a limited range of possible conjunctions. (Miodrag 85) 
Since the comics that have achieved legitimacy have historically done so by being adopted as a form of literature rather than fine art, it falling on the critics of that field to provide clarity about the medium's merits. Yet assuming that comics only occupy a place of literary value ignores the expertise that must be present to facilitate an understanding of how the image conveys complex narrative. Furthermore, shorter works are often overlooked due to their narrative brevity. In turn, this assumed exclusivity clouds the discourse, as a general standard of narrative length and complexity is hard, if not impossible, to define without creating serious issues that compartmentalize different visual narratives into subcategories. An example of current issues with such exclusivity in discourse can be seen in the debate concerning single panel cartoons and whether they fall under the "comics” designation. In her book Comics and Language Hannah Miodrag points out: "There is some disagreement over whether single panel cartoons should be considered as comics along with cartoons strips, serialized comic books, and graphic novels: generally, they are accepted as belonging to the same tradition, but are excluded by the likes of [Scott] McCloud in order to privilege the sequential aspect of strips” (Miodrag 86). 


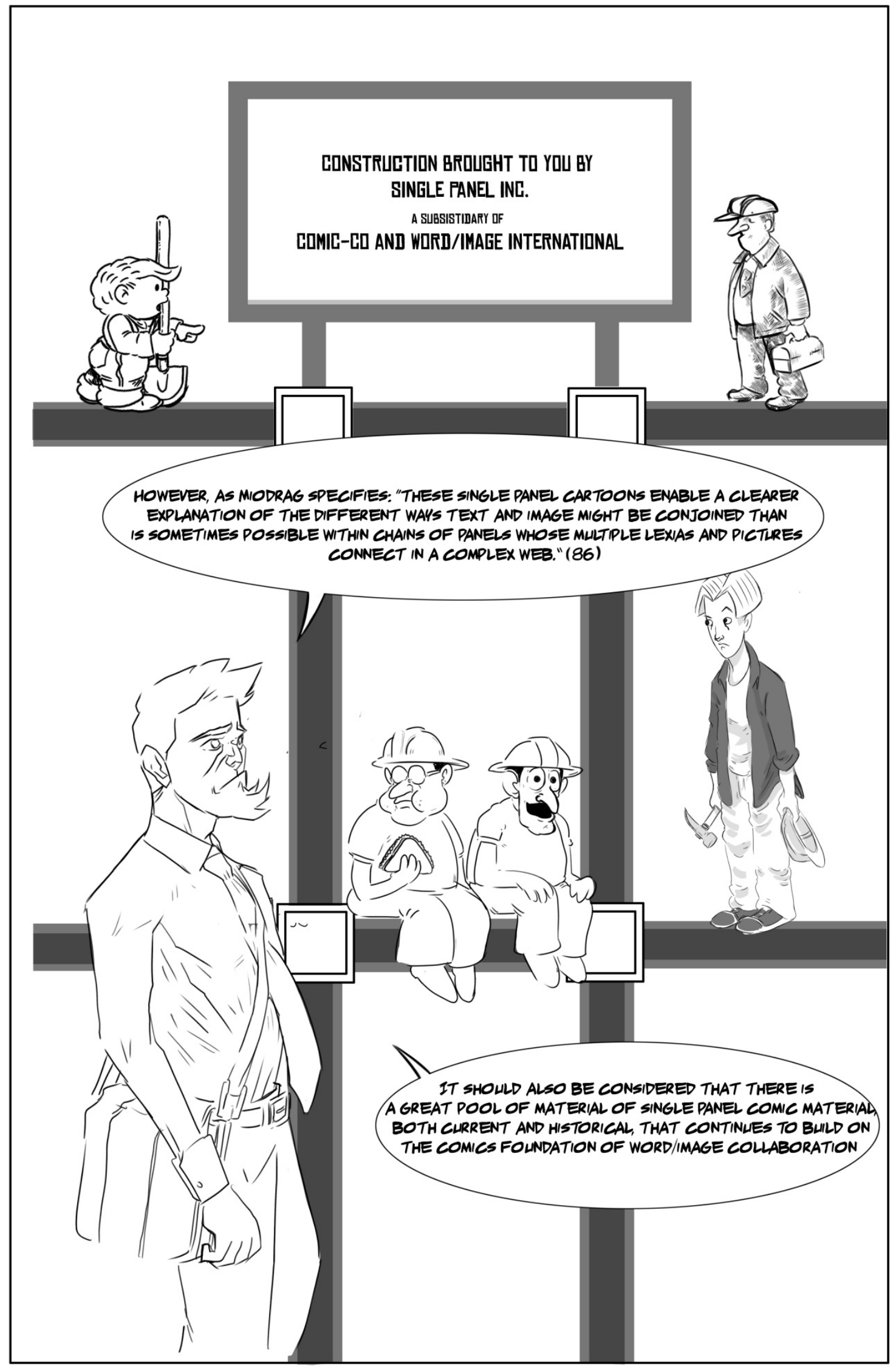


However, the issue of how to classify a comics narrative is not what has historically damaged discourse surrounding comics as a whole. The dismissal of the comics medium was not based predominantly on what constituted a comic narrative, but instead on what was contained within the narrative.

Comics have always been forced to endure the struggle of separating their content from the way in which they were popularized during different cultural eras, something that does not plague other media.

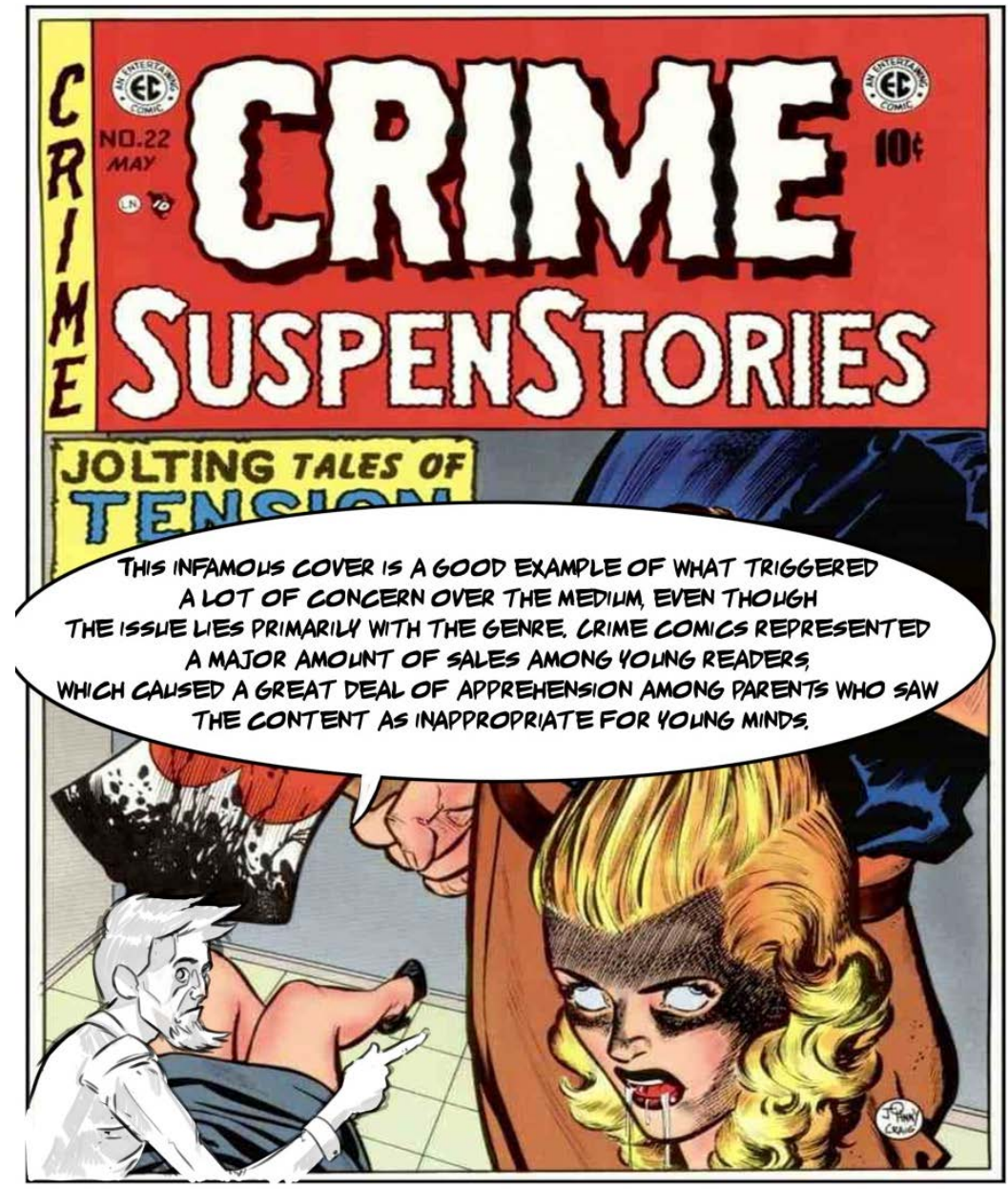

The search for legitimacy and desperate need for a legitimizing terminology can be linked to the negative language previously common in comics discourse due to the public's dismissal of the form as juvenile or immature. Miodrag confirms: "In part, the contention over terminology can 
be traced to a widespread desire to distinguish comics from illustrated texts. Most critics are keen to isolate interactions of words and images from other verbal visual forms, particularly those considered juvenile such as illustrated picture books” (86). Such separation from other popular juvenile formats is understandable as historically the discourse surrounding comics discussion has been focused on narrative content and its effect on children rather than on its potential literary value. In fact, in order to understand how comics have evolved it is essential to track how the industry was shaped by the assertion that the medium is suitable only for certain demographics.

Comics have historically occupied a low position within popular culture, ephemeral and reflecting only the current societal interests, focussed on appealing to the masses rather than maintaining artistic or literary integrity, and those who criticized the medium in the past were responding mainly to public reception instead of presenting a critical approach to the medium. In his book Comics vs Art Bart Beaty gives examples of how comics have been compared to “poisonous mushrooms” (18) or, by drawing on research from Reinhold Reitberger and Wolfgang Fuchs, as "the tool of a few newspaper publishers who wanted to extend their power and control of the market" (Beaty 19). This attack on the medium is an example of the historical issue of comics being viewed as the specific medium of young readers or the working class. The idea that comics have traditionally not contained complex literary narrative or high art is even mirrored by artists and writers within the comics industry, such as Robert Crumb. Crumb’s works, for example the "1969 strip entitled 'Drawing Cartoons is Fun!' [...] rejected the idea that comics constituted an art form” (Beaty 19), supporting the "badboy" image previously suggested in Beaty's book. Even Art Spiegelman, who can be seen as one of the "fathers" of the graphic novel, considers comics a medium dependent on a "common” audience: 
Spiegelman: The first comics were really born as a kind of extension of vaudeville. They were slapstick. These comics were disapproved of almost as soon as they were born because they were for the unwashed masses, the immigrant culture that was being acclimated to America, and reading the funnies wasn’t what you should be doing on Sundays. (Were you supposed to be reading R. Crumb’s Genesis or something? I don’t know.)[. . . . ] So the medium was born with a kind of unsavoriness. (Spiegelman 20)

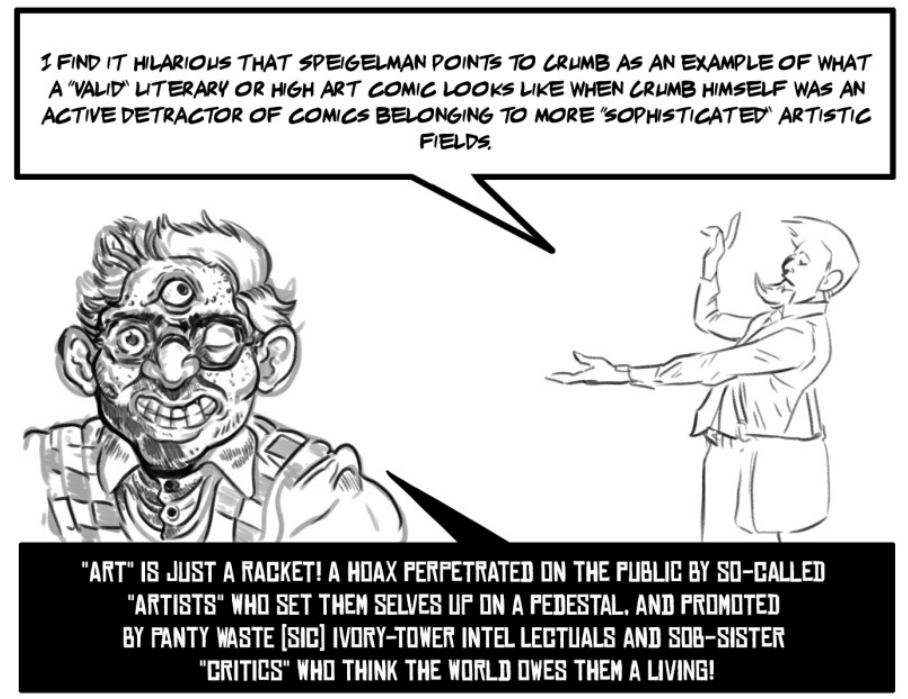

This association with "unwashed masses," indicating the general populace and more specifically the labouring classes, combined with the narrative content resulted in the word "comics" acquiring a pejorative rank in the literary field and dismissal as a result of association with popular culture. Beaty points out that even Groensteen, in his article “An Unidentified Cultural Object," refers to comics as a "bastard genre” (Beaty, Comics vs. Art 19) of hybridity and that comics are seen as "intrinsically infantile and are consumed by adults who are seeking to prolong their adolescence” (Beaty 19). Groensteen’s inference that comics are linked synergistically to children and young adult literature is not limited to one article; even when he defends comics as being a form of art and literature, he still reduces the medium to something that is "financially speaking available to everyone as is confirmed by those children who devote themselves to it” 
(Beaty 19). Groensteen's suggestion that comics belonged primarily in the hands of a juvenile audience, combined with its label as a "common" medium, has historical roots, given that its rise in popularity was controlled by a market of children. However, comics' label as a "common" medium should not necessarily correlate with its dismissal from scholarly consideration, as “Groensteen’s point is that comics scholars need to embrace this working-class and juvenile history - we should be questioning why we automatically make negative associations with things enjoyed by ‘common’ people and children” (O’Malley, comment on current section).

The influence of comics as a medium was at its peak in the 1940s, as Charles Phoenix points out in his dissertation "Classroom Comics: A Five-Part Narrative Recounting a Teacher Action Research Study Using Comics to Teach Academic Vocabulary in the Middle Grades”; in “1942, 25 million comic books were being purchased each month, and by one conservative estimate, at least ten children would read every comic book sold - leading to the biggest [reading] fads among children in world history” (Phoenix 57). The unprecedented popularity of this "fad" caused concern among the public, as the industry was both creating and responding to demand through marketing directed at youth, the most impressionable and vulnerable members of society. This reading "fad" did not dissipate naturally, as the fall of the Golden Age of comics can be attributed to "the entire nation turn[ing] against comic books" (Phoenix 61) and the specific regulation which came into being in response to the public's concern surrounding an industry geared toward a youth market. Arguably the most public dismissal of comics can be traced roughly to the 1950s, a time when the comics medium was literally put on trial. At the forefront of this crusade was psychiatrist Fredric Wertham, whose Seduction of the Innocent was a viable scholarly criticism of the medium. Wertham claimed that comics were a major contributor to a perceived moral decline in children, leading to violence, drug use, delinquency, 
and illiteracy: "The general lesson we have deduced from our large case material is that the bad effects of crime comic books exist potentially for all children and may be exerted along these lines: 1) The comic-book format is an invitation to illiteracy. [...] 8) They may tip the scales toward maladjustment or delinquency. Crime comics are an agent with harmful potentialities” (Wertham 79). Seduction of the Innocent established much of the dismissive language that is still used today to describe comics as a medium and helped confirm the dismissal of image in favour of the written word. Wertham asserted that: "Comic-book readers are handicapped in vocabulary and reading because in comics all the emphasis is on the visual image and not the proper word" (125). The term "proper word" demonstrates the essential issue that comics face, in that the medium does not conform to the standards outlined by other "proper" media. After his archive was made available to the public in 2010, Carol L. Tilly discovered that "Wertham manipulated, overstated, compromised, and fabricated evidence — especially that evidence he attributed to personal clinical research with young people — for rhetorical gain” (383). Yet at the time of his original publication Wertham's image was that of an outspoken advocate raising the alarm over the risks of comics to young children. It is important to note that Wertham was not alone in his villainization of comics: "Beginning in 1946, and against the backdrop of the collective anxieties of the early cold war, the diverse, heterogeneous criticisms leveled at comics magazines since the late 1930s gradually coalesced into a moral panic that singled out their allegedly crime-inducing nature” (Gabilliet 29). Long before Wertham became the figurehead for the movement, "as early as 1949, spontaneous comic book burnings erupted in cities and towns across the United States” (Phoenix 61); what Wertham did was herald the first "legitimate" and critical attack on the medium through Seduction of the Innocent. Wertham had already begun preparing the American public for his critical publication by releasing articles between 1948 and 1954, such as "What 
Parents Don't Know About Comic Books,” which ran in the Ladies' Home Journal in November of 1953, and set up anti-comics rhetoric.
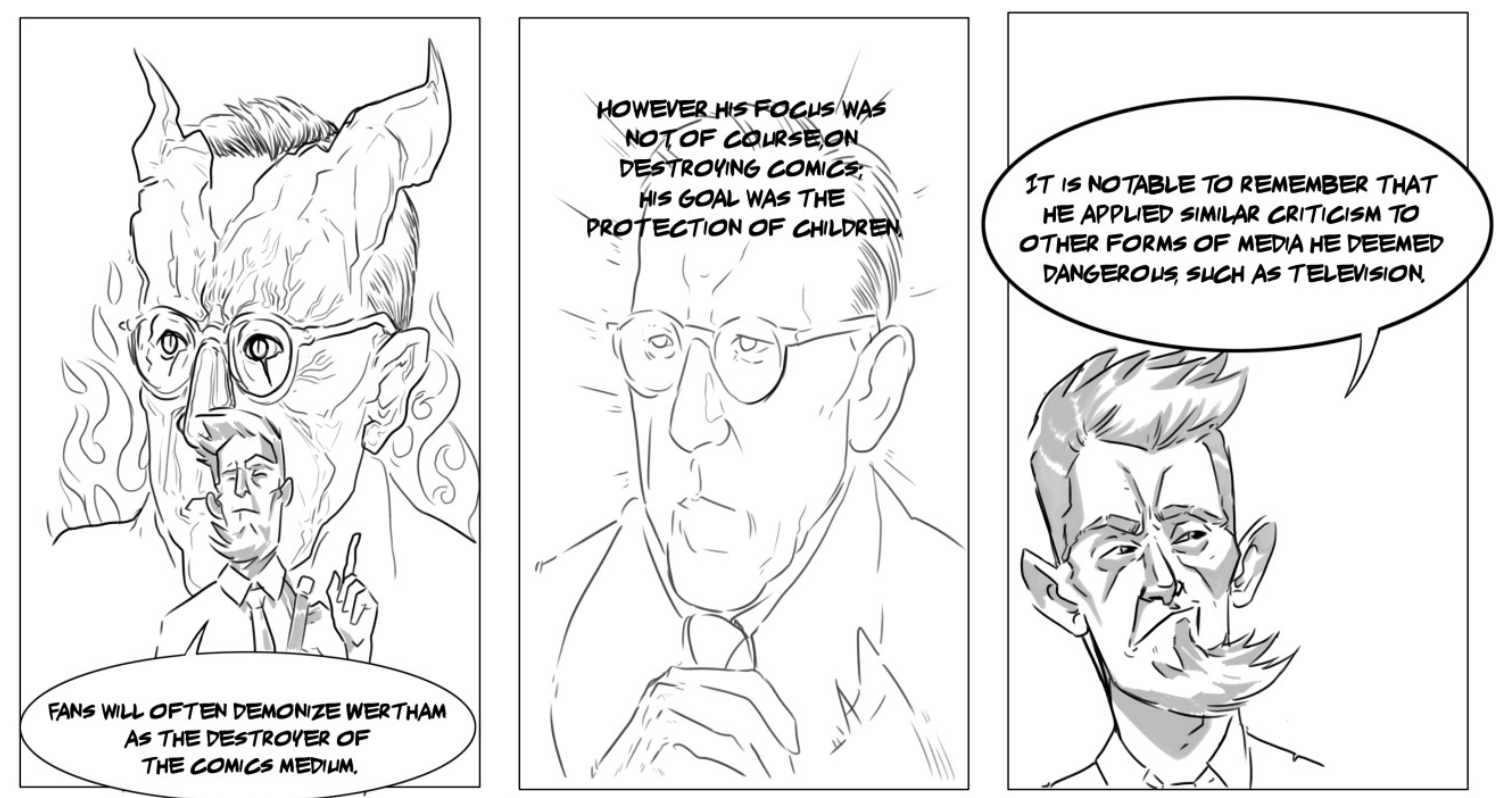

Wertham recognized the concerns regarding delinquency and illiteracy of children that were common among American parents and capitalized on them by placing himself at the forefront of the charge against the comics medium and its perceived damaging effects on young readers.

Wertham's work eventually led to his inclusion in the United States Senate Subcommittee on Juvenile Delinquency as a prime witness/expert, and his testimony is famously credited as being one of the main reasons for necessitating regulation which followed the hearings in 1954. This regulation led to the implementation of the Comics Code Authority, which, according to Jean-Paul Gabilliet's Of Comics and Men caused "fifteen of the forty-two publishers [to] go under during the summer of 1954. Deprived of over a third of its representatives, the comic book industry found itself perceptibly weakened” (Gabilliet 41). The most influential effect the Comics Code Authority had was in its implementation of the Comics Code, which through its different versions cemented that "comic books were intended for the child reader and should contain nothing that would be inappropriate for young readers” (Nyberg 
1742). The Comics Code brought about harsh rules and restrictions on the publishing and sale of comics. In his article "Telling stories about storytelling: The metacomics of Alan Moore, Neil Gaiman, and Warren Ellis,” Orion Ussner Kidder explains: “The Code itself is a direct response to accusations and complaints made by the American anti-comics movement of the forties and fifties. That movement was, predictably, concerned with depiction of sex and violence, but also criminality and literacy" (64). This forced regulation of the comics medium solidified the industry's place within the confines of children's entertainment, establishing children as the only assumed consumers of the medium, and effectively limiting the content that could be explored. To ensure that the material met acceptable moral levels, the original Comics Code Authority included amongst its articles of censorship depictions of "delinquency," "horror," "decency of dialogue," "religion,” "nudity and the female body,” and "marriage and sex” (Gabilliet 43). Interestingly, the sentiment that comics cannot hope to deal with "mature" themes can be linked to them being censored and prevented from doing so. Amy Nyberg confirms this in Seal of Approval when discussing the updates made to the Code in the 1970s: "Despite its softened stance, the 1971 code represents a lost opportunity for the industry. Its reaffirmation of comic books as a medium intended for children effectively shut the door on the possibility of attracting a broader audience for comic books” (Nyberg 1924-1925).

Another theory is that critics like Wertham were simply responding to the challenge that comics represented to the traditional use of sequential art in narrative. At the beginning of Seduction of the Innocent Wertham specifies: "our study concerned itself with comic books and not with newspaper comic strips. There are fundamental differences between the two, which the comic-book industry does its best to becloud. Comic strips appear mainly in newspapers and Sunday supplements of newspapers. Comic books are separate entities, always with colored 
pictures and a glaring cover" (14). In this initial specification of "strips” versus "books” Wertham demonstrates the differentiation between the comic book industry and those comic strips that had been part of American publications long before the popularity of the medium during the Second World War. In his distinction between the comic strip and the comic book Wertham does not distinguish between the medium of comics and the genres made popular within comics. The structure of comic strips does not always hold to a uniform standard, much like any other medium. Yet Wertham’s attack on comics avoids discussing strips as if to assert that the qualities of one versus the other are clearly defined, which is not the case. Wertham's need to differentiate between these two forms of comics is a direct justification for the subsequent emergence of the graphic novel.

According to Gabilliet, part of Wertham's effectiveness in swaying the American public was due to the "three rhetorical tropes" (231) that he employed in his campaign against the comics industry: a metaphor in the presentation of comics as a habit-forming drug, the personification of "the industry" as a powerful and vengeful Goliath, and the casting of Wertham himself as a lone heroic crusader in a fight to "save the children.” The first and second of these are most germane to the argument of this essay, in that Wertham conflated the reading of a comic book to an addictive drug that induced a desire to commit crime, which he backed with a "self proclaimed objective, scientific study” (Gabilliet 231). The association of comics with drugs not only lowered their status as a form of literature but removed them from the literary discourse completely, changing the focus of any argument concerning the reading of comics to issues of moderation, indulgence, and substance abuse. Wertham even went so far as to make direct links to comics and physical drug use by linking the two as symptoms of each other: "Most critics of comics, including Wertham, conceded that 'not every comic book is bad for children's minds and 
emotions.' Wertham, however, derogated these claims with statements such as the following: 'All child drug addicts, and all children drawn into the narcotics traffic as messengers, with whom we have had contact, were inveterate comic-book readers’” (Tilly 388). In modern discourse, the cliché adage that comics will "rot your brain” may be a remnant of the link between comics and substance abuse.

In addition, Wertham was effective in his removal of the individual from the creation of the comics medium. According to Gabilliet, throughout his attack on the medium Wertham made “references to ‘the industry,’ presented as a homogenous monolithic and inhumane mafia” (231). This demonization of the publishers attributed a sinister connotation to the "glaring covers," a big factor in drawing in new readers; the images were presented by Wertham as not demonstrations of art but instead tools used to draw in and capture vulnerable young minds, pulling them away from good and moral ventures. Interestingly, although Wertham did not champion censorship of comics specifically for children he did state that: "I have never come across any adult nor adolescent who had outgrown comic-book reading who would ever dream of keeping any of these 'books’ for any sentimental or other reason” (Wertham 89). In this way, Wertham moved the discourse away from the quality of the medium and onto the vulnerabilities of the youth of the time. In addition, the positioning of the "people” against the faceless industry facilitated the dismissal of the medium throughout various ages of comics' popularity. The focus on the industry as a faceless collaborative force removed the human elements inherent in the creation of a comic. Whereas other literary and artistic formats were associated with creators who could be held accountable for the content of their work, comics were associated with publishers and owners, not writers and artists. With this, it became possible to attack the industry as a whole and not just specific questionable works. Part of the reason for the success of the 
graphic novel, as will be discussed further, was the elimination of the faceless collaboration through the placement of accountability on individual creators.

The impact of these negative attitudes and language can still be felt today, with the term “comics" still widely associated with basic narratives, sensationalized tabloid style images, or simple literature, which only in rare cases are worthy of academic consideration. Labelling a piece of literature as a "comic" can have radical effects on how it is viewed. Historically the best example of this can be seen in the case of MAD Magazine's circumvention of the Comics Code. Originally started as a comic book in 1952, MAD changed its designation from "comic book" to "magazine” in June of 1955. Its publishers re-branded by increasing its page count and the number of text-only parody articles, thereby avoiding the harsh legislation to which other serial publishers at the time were subject. This simple change had a lasting effect as the format of the MAD Magazine has changed little since its 1955 alteration. In this example the publication borrowed the credentials of text-dominated publications in order to add value. Even though the publication contained the majority of comic content as it did before, by including more text and satirical/parody items the magazine was able to placate the public's concerns and avoid censorship.

It is hard to imagine how the reading of any literary medium might be considered degenerative, as it can be assumed that reading in any form demonstrates literacy. In her book, Narrative Structure in Comics: Making Sense of Fragments, Barbara Postema discusses the issue: "Writing about comics, whether the aim is to address their history or to analyze their content from a social, cultural, or narrative point of view, inevitably leads to a discussion of their formal qualities” (XIII). Contemporary discussion is centred on the effectiveness of image and text working in conjunction, but it took another important reclassification step before this 
evolution in discourse could be possible. The reclassification of certain comics as "graphic novels" in the latter part of the $20^{\text {th }}$ century can be seen as an attempt to distance comics from the negative connotations caused by historical linkages to children's media and its pedestrian place in popular culture. However, in adopting a new title or designation, publishers and creators bowed to the critics of the medium who had never fully embraced or understood its merits; in doing so the industry attempted to conform to standards which were inherently linked to valuable literature in order to achieve legitimacy and a standard of quality that does not address the medium's needs. Spiegelman discusses how the labeling of graphic novels was based on borrowing the merits of existing literary formats: 

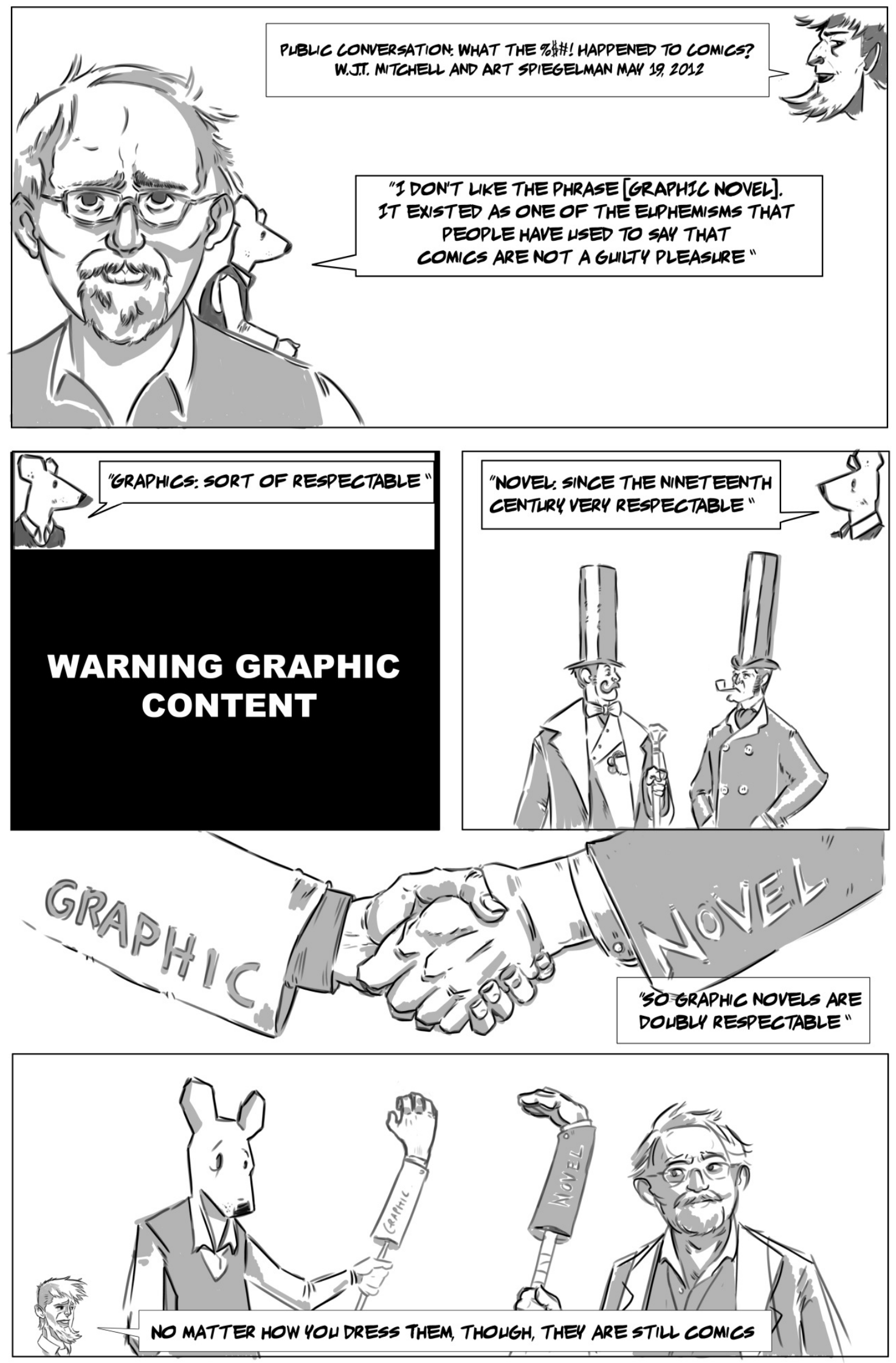


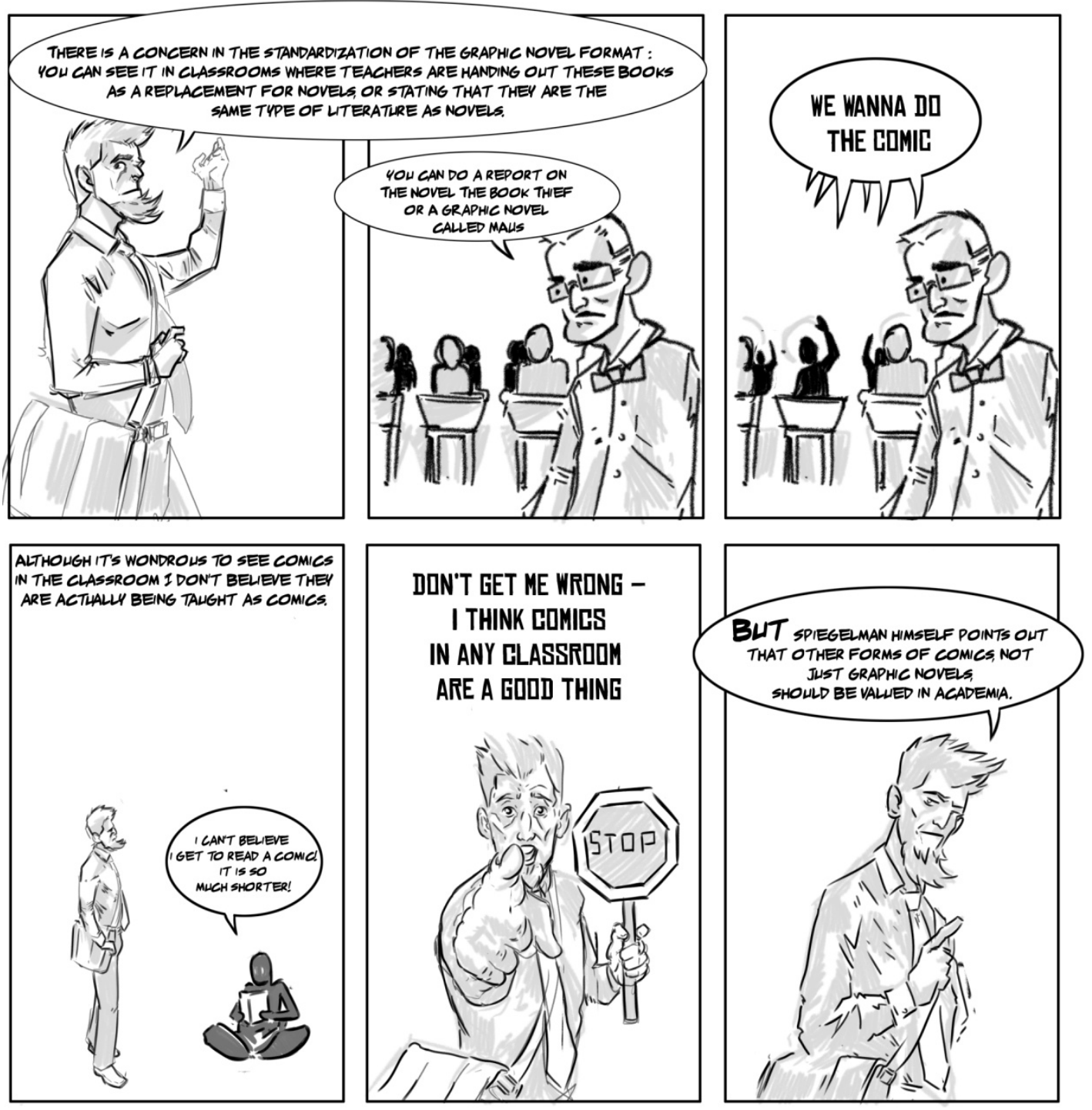

The branding of the comics medium has been paramount in ensuring that quality narratives are not dismissed from critical review. The graphic novel is an attempt by the industry to assert the literary value represented by the medium of comics. According to Kidder:

While they seem to privilege the blend between text and image, it is clear that the textual or literate qualities of comics tend to predominate. This can be seen in the widespread adoption of the term "graphic novel" as a gentrifying replacement for "comics." With this term, as Catherine Labio has pointed out, the visual element serves primarily as an 
adjectival modifier for the literary element. In other words, comics achieve their aesthetic value in these frameworks through the library, not the gallery. (Kidder 34) The word "graphic" in its relation to the word "novel" is an adjectival modifier that confuses the observer as to the content within. "Graphic" does not indicate the use of images for narrative purposes as comics have come to represent, but rather that the "novel” will either contain images or content that are meant for a mature audience. The observer, then, is not only left to figure out what is contained within the pages of the graphic novel, but must judge the contents through standards attributed to the novel medium, as the title itself suggests, thereby subjugating the image.

Kidder's argument is supported historically in the remarketing of the comics as graphic novels in the 1980-90s. The rise of the graphic novel can be attributed to the gradual inclusion of the comics medium into the "general book market" (Gabilliet 98). The designation "graphic novel” has included a variety of formats, such as collections of previously published comic book runs or newspaper comic strip collections. The variety of what is contained within the broad label of "graphic novel" is not done out of necessity or practicality, but as an attempt to slap a veneer of homogeneous respectability on a heterogeneous mass of literature and art. The popularity of the format met with scattered success until 1982, when Marvel began publication of its "Marvel Graphic Novel” line. Although slow, the penetration into the traditional book market heralded a new era in the sale of the comics medium, as it was no longer exclusively the domain of specialty stores or magazine racks: "In several years, comic books found themselves established on shelves designated for "Graphic Novels" and were no longer exclusively shelved in the "Humor" sections, as had been the case since the 1950s" (Gabilliet 99). This redefinition fundamentally changed the way publishers approached the construction of narrative and shifted 
comics’ place in what Pierre Bourdieu defines as the "economy of cultural goods” (1); “instead of telling a new short story each month, [writers] wove entire stories structured over six or eight consecutive issues that were formatted for their ultimate publication in trade paperbacks. DC particularly enacted this policy with series such as Sandman by Neil Gaiman, Preacher by Garth Ennis [and others]” (Gabilliet 100). The need to conform to practices outside of the comics industry and replicate those of "legitimate" literary publications is what ultimately drove the industry to adopt the format of graphic novels as a way of rebranding their licenses. If comics sought to establish themselves as "legitimate" they would be forced to acknowledge their historically "illegitimate" place:

To the socially recognized hierarchy of the arts, and within each of them, of genres, schools or periods, corresponds a social hierarchy of the consumers. This predisposes tastes to function as markers of "class.” The manner in which culture has been acquired lives on in the manner of using it: the importance attached to manners can be understood once it is seen that it is these imponderables of practice which distinguish the differentand ranked-modes of culture acquisition, early or late, domestic or scholastic, and the classes of individuals which they characterize (such as “pedants” and mondains). (Bourdieu 2)

Bourdieu indicates in Distinction: A Social Critique of the Judgement of Taste that such status is due in large part to "educational level” (1); because comics had been considered to exist within the realm of children's media and working class consumers, the graphic novel had to distance itself from this demographic. As indicated by Spiegelman in the comic above, this association was circumvented by placing comics among "respectable” formats of literature, such as the novel. In this way the graphic novel borrows from previously established 
traditions, as Bourdieu indicates: "Culture also has its titles of nobility — awarded by the educational system — and its pedigrees, measured by seniority in admission to the nobility" (23). In order to draw in new readers comics were forced to borrow from a medium that traditionally held a higher placer in the cultural "hierarchy.” This is evident through the significance placed on text over image during a period of re-emergence for the medium, often referred to as the "Dark-Age" of comics in the 1980s and 90s. Kidder specifies that the DarkAge represents the shift away from the established Silver-Age influential Revisionists. The "Dark Age” works of Alan Moore, Neil Gaiman, and Jim Starlin include comics such as Sandman, Black Orchid, The Life and Death of Captain Marvel, and Swamp Thing, which altered the way in which comics were perceived during this time period. The Revisionists were writers, "who have been instrumental in the generic and formal revision of American comic books; thus, they and many of their contemporaries have been called 'Revisionist' creators” (Kidder 1). The emerging format these writers contributed to necessitated new terminology that could be applied to comics, which put greater emphasis on a single or complete narrative versus the collaborative or serial publications that came before, giving rise to the widespread use of the term "graphic novel." This was accomplished by shifting the focus from a collaborative effort of multiple artists and writers to the singular writer as the driving force behind the narrative, as well as re-inserting realism into a genre that was primarily focused on the fantastic. The impact of previous eras of the popular traditional superhero are evident in Neil Gaiman's and Alan Moore's approaches to the genre. By adapting and evolving the traditional elements of both genre and function of the comics medium the graphic novel demanded a new place in the "social hierarchy of consumers” (Bourdieu 2), which allowed the Revisionist writers during the DarkAge to force a reclassification of comics. The market began to draw readers outside of children's 
literature and pulp and encouraged the rebranding of the comics medium in order to reflect its new place in literary and artistic discourse.

Thus began a shift in how the medium was approached by creators and readers alike, which in turn changed its popular perception. Again, this supports Beaty’s claim that "the literary turn in the study of comics has been a tendency to drive attention away from comics as a form of visual culture” (Comics vs. Art 18). This shift from the standard collaborative style to one controlled primarily by the author can be connected to the above-mentioned indication that critics give more value to work with a singular creator. The graphic novel was a shift in the “economy of cultural goods” for comics, as: “The pure intention of the artist is that of a producer who aims to be autonomous, that is, entirely the master of his product, who tends to reject not only the 'programmes' imposed a priori by scholars and scribes, but also - following the old hierarchy of doing and saying - the interpretations superimposed a posteriori on his work” (Bourdieu 3). The Revisionists and writers of graphic novels stood outside of both traditional comics and literary formats, drawing from, but not belonging to, either cultural object. Writers of the Dark-Age were made the focus of the marketing for their work and the success of their prose was used in advertisements in place of the traditional brand associated with the superhero genre (a collaborative effort by multiple artists and writers). Marketing for pieces in the Dark-Age was not focused on buying the "newest Batman comic,” but instead on buying the "newest Frank Miller comic.” 
Seravalle 30
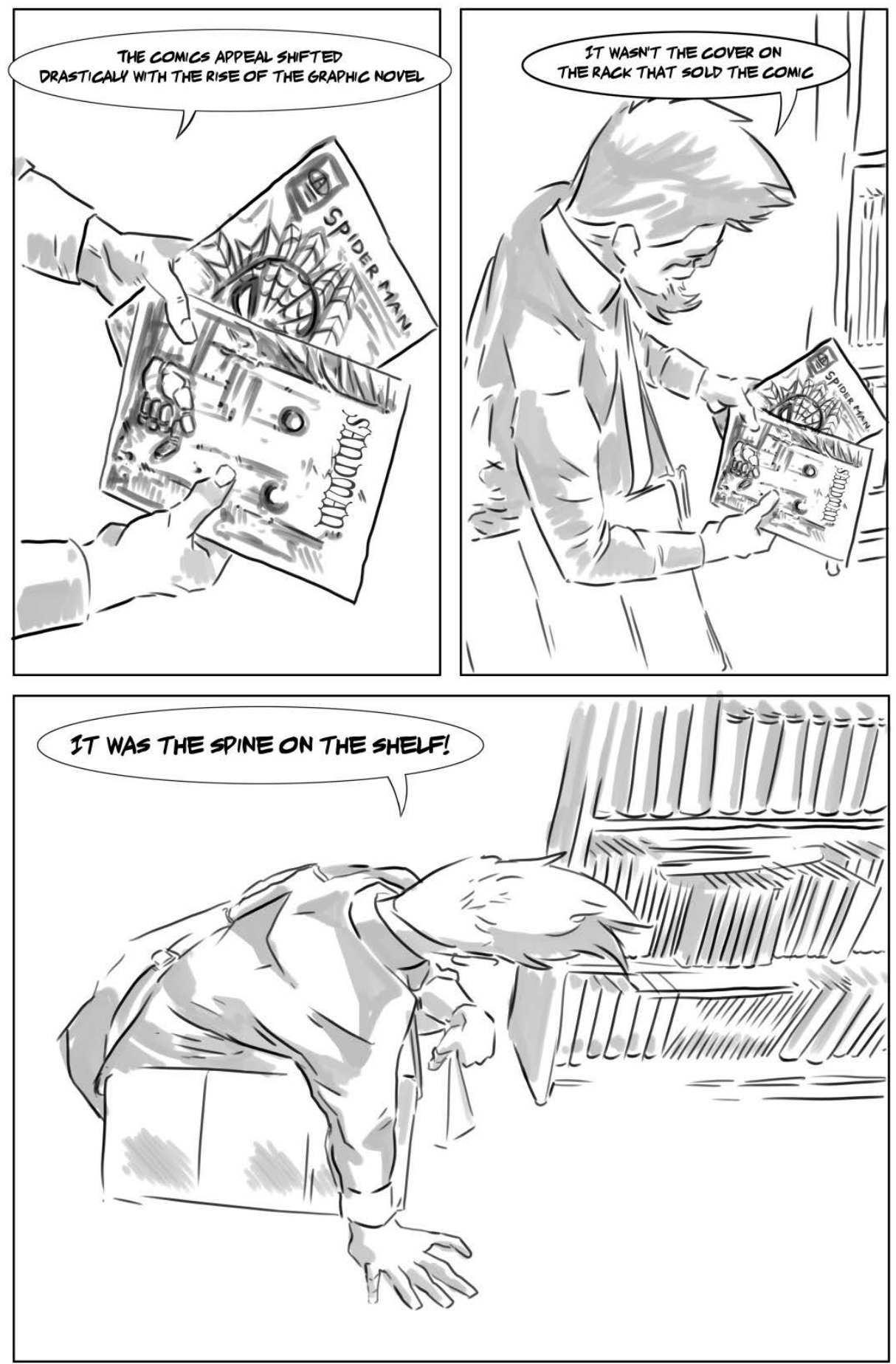

The industry was borrowing the credit associated with writers not traditionally affiliated with writing comics; the role of the Revisionist writer separated what was essentially a fluid position in previous generations, as "part of their [The Revisionists'] ability to 'revise' American comics comes from their simultaneous insider/outsider status” (Kidder 9). In this way, although 
Revisionist authors were acting as comics writers, they were not seen as part of the traditional industry. Comics went from industrial creation to individual inspiration. The important thing to highlight about this transition is that it shifted attention to the quality of the narrative through writing alone and not the combination of image and text. In doing so, the public's perception of the value of a graphic novel was based primarily on its text.

The idea that Revisionist writers represented a role similar to a more traditional author of a novel format was supported by important changes that happened within the industry. At the time, Moore, Gaiman, Ellis, and Miller were breaking new ground, as the medium was neither suited for nor accustomed to conveying a novel-length narrative. During the Dark-Age, serial publications began being grouped into single-author runs and were sold as a collection that represented a narrative that could be read without knowledge of the rest of the genre. As an example of longer narrative format, one might consider Neil Gaiman’s Sandman. Sandman’s greatest strength is that it transitioned a traditional fantasy/horror comic into a hybrid format that could encompass various elements, such as horror or romance, while maintaining the style of comics before it. In doing so, Sandman represented a push for more complex narratives in serial publications and hinted at how the medium could evolve. The first graphic novel-length collection of Gaiman's work, Preludes \& Nocturnes, follows the main character, Morpheus, as he overcomes adversity and sets out on a quest to discover his identity as a being of great power. In Karen Berger's introduction to Preludes \& Nocturnes she points out that, at a glance, Gaiman's story represents the cliché superhero quest and origin story. Says Berger: "in the hands of a different writer, the seeds that were planted in this fertile story ground could have borne a Blevel fantasy/horror title” (Berger ii). Interestingly, in her praising of the comic, Berger puts emphasis on Gaiman's writing as the main component to the narrative's success, with a limited 
mention of the artists' contribution to the overall conveyance of the story. Berger does praise the artists for their contribution but her commentary has more to do with the images’ impression and less as to their part in the narrative:

“... Sam Kieth, Mike Dringenberg and Malcom Jones III— provided the right atmosphere for Morpheus’ haunting origin story. Like Neil, they were relatively new to comics and were evolving their own distinctive styles. Sam did wonderful portrayals of Cain and Abel, and his visceral renditions of Hell and its gruesome inhabitants were truly horrifying. Mike most notably created the perky goth visual for Death, and his interpretation of Morpheus is probably one of the best ever done. Malcolm’s illustrative line work brought a cohesive and definitive look to the overall series.” (Berger ii) Berger continues by praising the efforts of Dave McKean as well, but she ends her paragraph with Gaiman's contribution again and states: “The first volume of the SANDMAN series is very much a work in progress; that of a talented writer who eventually honed and refined his skills and progressively developed his initial concept” (Berger iii). Berger, limiting the collaborative contribution that the artists had in the creation of Sandman, places Gaiman and the writers of similar comics on a pedestal; she attests that the greatest value of the narrative lies in its writing, as in her words Gaiman's work “leaves room for writers to explore and create new dreaming territory, denizens, and dreamers alike” (Berger iv). Berger's focus on Gaiman’s writing can be seen as an example of how even within industry the role of the writer was elevated in determining a comic’s merits.

Arguably the ending of the collection is what gives it its highest merit and a visual in the final chapter adds significantly to the narrative's quality. In the final chapter of Preludes \& Nocturnes Morpheus receives his payout by being restored to his god-hood but he does not 
receive his moral victory, which was conventional for other superhero comics: although characters in the comics struggle, historically they always do the "right" thing and remain heroic in their disposition. Kidder states: "this point may seem self-evident, and indeed it is, but superhero comics for several decades relied on a dim, if fanciful and compartmentalised, belief that super heroic morality is just a fantastic extension of one’s moral duty” (Kidder 94). In the final chapter it is Morpheus's sister, the physical embodiment of Death, seen traditionally as a force of absolute evil, who comforts Morpheus and does so in the appearance of a positive and happy young woman (juxtaposed with her traditional "goth” appearance). According to Berger this is the moment at which Sandman represents a true first attempt at changing comics, as it invokes a sense of realism and humanity that is absent in the superhero genre where most of the main characters are known for their godlike power and incorruptible natures. Focusing on the representation of omnipotent beings, Gaiman also demonstrates a new concept of muting the outrageous and easily identifiable imagery of the superhero genre. Morpheus abandons his hero accoutrements and upon conclusion of the narrative reveals his final form as a humble and nondescript man in plain clothes. In her introduction Berger talks about the importance of this issue, “The Sound of Her Wings”, but limits her praise to Gaiman alone: "It was the element of humanity and interpersonal relationship that started coming through in Neil’s work” (Berger ii). Yet the conveyance of the dynamic parallel of Morpheus's godlike nature and his humanity could not be achieved without Dringenberg's artwork, as it factors into the exchange between the two characters. Without his vision, in conjunction with Gaiman's writing, the narrative might not have had the impact that Berger commends. 
Seravalle 34

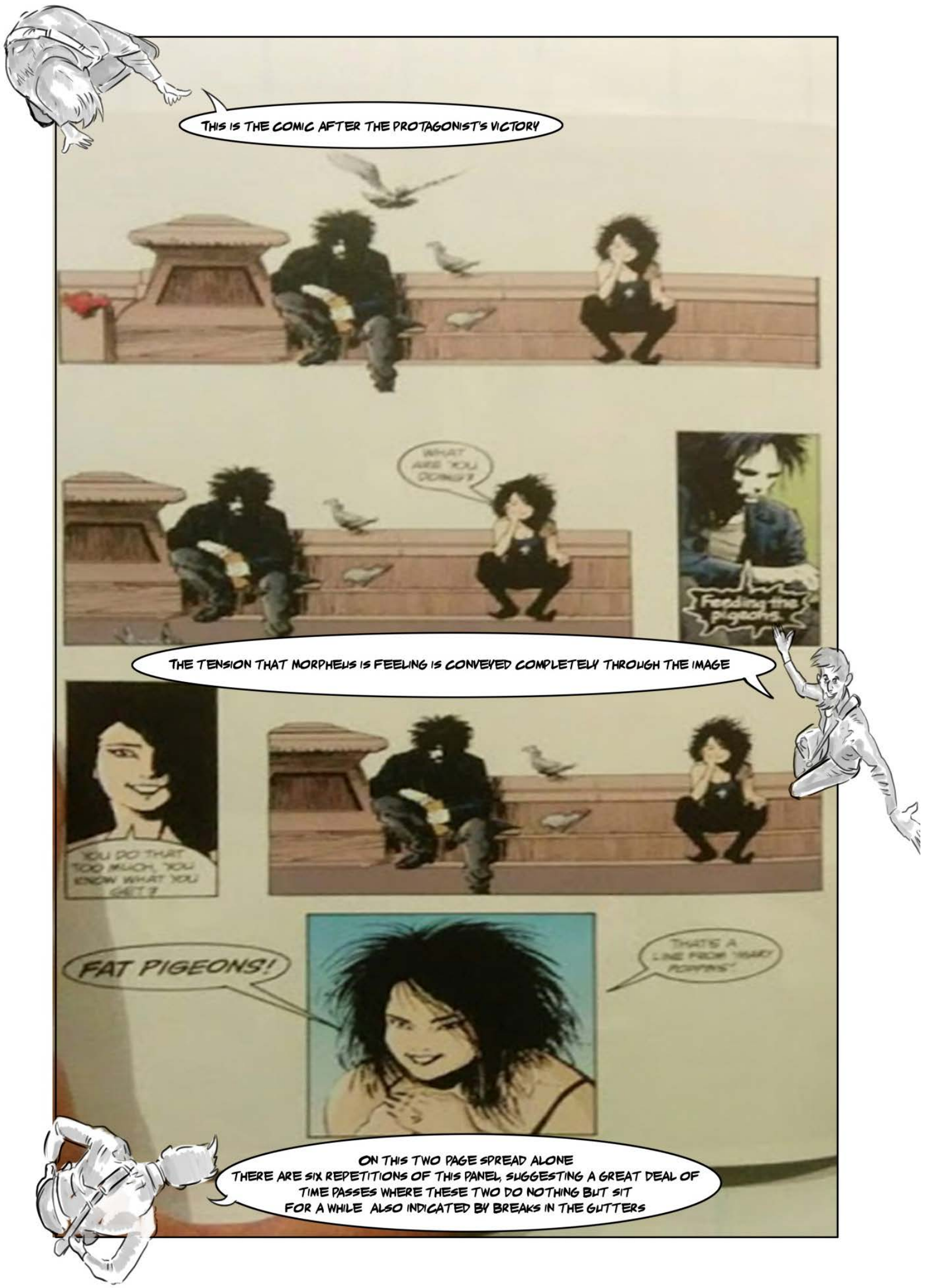




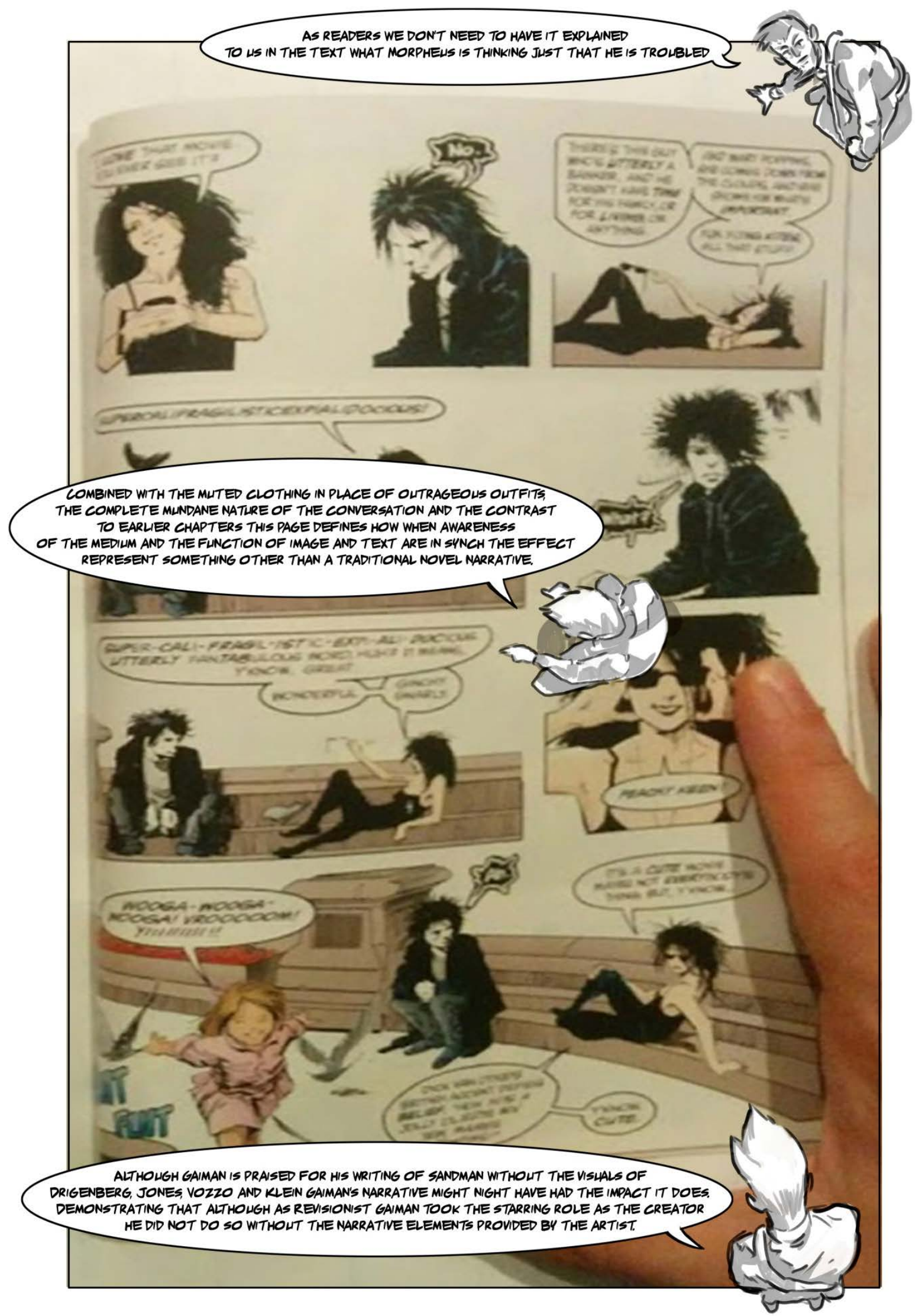


There seems to be a need to qualify comics through other media that make use of visual and prose hybridity, such as film or animation. Yet writers and artists in the industry who have experience in a variety of media fields point out that consideration of the visual does not always translate to the comics format effectively. In an interview, when Daniel Clowes was asked whether he utilized any of his screenplays for comic adaptation, he replied: "I think I should turn these stories into comics. But then I realized that it would take as much work to adapt a screenplay into a comic book as it would to start from the beginning. It's a very different thing” (334-335). Clowes goes on to explain that comics and the visuals that go into their creation are unique to the medium and substitution of the storyboarding of one format does not often translate into the other. As discussed above, due to their historical marginalization comics tried to establish credibility through the merits of existing media; however, in doing so the comics medium begged comparison to those media. The presence of similarities between the media does not justify analyzing them through the same lens. It is also meaningful to remember that comics were a dominant industry at their peak and stood on their own merits. Comics served as the source of iconic characters and worlds which have been represented in a variety of other media forms since their inception. By holding comics to another medium's standard the discourse surrounding them is weakened because the language being used in the analysis is not originally meant to discuss what is, in fact, a distinct medium in its own right.

Part of the process of exposing the subjugation of image is identifying to what standard the image is being held. Scholars such as Postema and Miodrag link the image with iconography or a form of diagram: “However, notwithstanding talk of image-text 'blending' or 'unity,' text inevitably signifies in a completely different way from even the most abstracted of images and the most conventionalized of icons” (Postema 81). A definitive format or standard to the use of 
image in the conveyance of narrative cannot be established in the same way as what exists for text. Although utilizing elements of the practice, image in comics cannot be strictly iconographical, and even the most direct utilization of an icon’s function must be argued in a comics narrative. In addition, even when maintaining traditional conventions of picture books image cannot be assumed to be illustrative to text. The importance of clarity in designation may seem semantic; however, the need to differentiate between illustration and image as employed within comics stems from a number of perceived detrimental effects associated with illustration. Miodrag points out that "the desire to differentiate comics from kids' picture books is frequently made explicit, although I have never heard that form referred to as 'hybrid' outside of the comics scholarship that holds this illustrative 'hybridity’ apart” (89). This could be due in large part to the fact that within the literary industry, the use of image in narrative is still predominantly isolated to children's literature and therefore not suggested for the conveyance of mature narratives. Miodrag suggests that the use of illustration in picture books represents “noninteractive copresence [that] might better be described as ‘juxtaposition’ - if indeed another term than 'illustration' is needed to designate its operation - and it is useful to any analysis of comics to distinguish this from other kinds of visual verbal conjunction” (Miodrag 89). Nodelman furthers this analysis by explaining that:

While picture books also work by relating sections of text to specific images, they create a different dynamic by stripping that relationship down to the conventional one-imageplus-one-text accompanying it per page or two-page spread. In picture books, indeed, each set of image and text implies a relationship something like that between a painting on a gallery wall and the printed information posted near it about its name and its artist, 
or like that between an illustration in a magazine or newspaper and its accompanying caption or headline. (Nodelman 438)

This "one-image-plus-one-text” pattern can be seen in a great deal of comics works, but although there are similarities between the two, ““[W]ithin the paged multiframe that constitutes a complete comic, every panel exists, potentially if not actually, in relation with all the others. This totality $[\ldots]$ responds to a model of organization that is not that of the strip nor that of the chain, but that of the network' (Groensteen 146). As a result, “The strip, the page, the double page, and the album are nested multiframes, systems of increasingly inclusive proliferation” (Groensteen 148 qtd in Nodelman 439). The distancing of comics from other media is therefore a necessity, as although a comic may appear similar to other media that utilize visual elements to convey information the function of these elements in comics is specific to the medium.

The second goal to identifying the standard for image, as suggested by Miodrag, concerns the need "...to downplay the form's replication of the operations of literature and art" (Miodrag 89). Again, the reasons for this can be linked to industry, as the comparative element of other forms of literary prose or artistic construction and their scale for quality don't factor in considerations required for adequate analysis of the comics medium. As stated earlier there is some merit to this assertion as comics cannot simply be analyzed through traditional literary or artistic lenses but require the knowledge of both in order to come to consensus on the multitude of levels of narrative conveyed through them. This observation leads into Miodrag's third point that it is necessary to have an understanding of both visual and textual critical theory when addressing comics, since "comics do not only replicate the effects of these two art forms, but also utilize their own, form specific devices, such as panel sequences, page layouts, and speech balloons” (Miodrag 89). What this suggests is that even if a comic features quality prose with 
carefully constructed art, a critical eye must consider whether the two methods are actually merged and, if not, whether this is an intentional attempt at evolution of the comics medium.
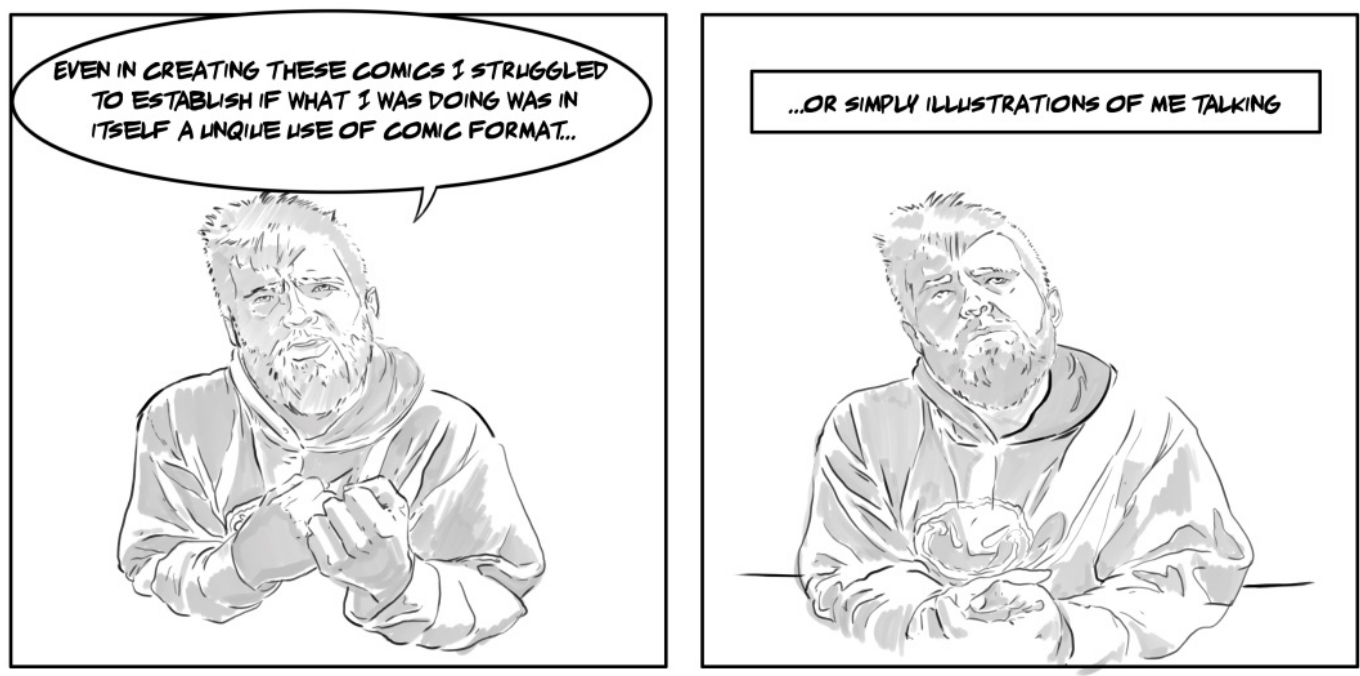

This necessitates language and analysis that are specific to the comics medium and that evaluate image and text on equal terms (as opposed to placing one at the service of the other).

What complicates the distinction further is that the text in comics is often critiqued in absence of a consideration of the unique formatting of the medium. There is little common knowledge on how best to utilize text and in many cases the formatting of the word reverts back to the established traditions of written narrative outside of the comics format. The need to qualify the writing within the comics medium can be seen in the lingering effect of the Comics Code, as although the Code had lost the majority of its power in the early 2000s its symbol still remained printed on major publications. It wasn’t until 2001 that Marvel abandoned the Code, while DC and Archie did not abandon it until 2010, well into the age of graphic novel production. Regardless of whether publishers followed the Code in its later years, within its edicts lay crucial wording on the editorial practices of the written word within comics narratives:

In reaction to that public image, mainstream publishers likely wished to make sure they incorporated a certain minimal amount of textual content in comics, so that comics could 
not be accused of causing illiteracy again. In the early sixties, when the comics controversy was a fresh memory, and the Comics Code was still new, being seen to promote reading among youth would certainly have been a concern to publishers. (Postema 100)

Critics' claims about the "poor” quality writing in comics were addressed in the "Comics Code through its specific guideline concerning “good grammar.” This call for good grammar was included in subsequent reiterations of the Comics Code starting in 1954 until 1989” (Gabilliet 313-322). Implementing “good grammar” in comics is problematic, however, as in many cases text in a comic narrative is meant to mimic speech and intentional colloquial wording and slang may be crucial in creating realistic dialogue that maintains verisimiltude. Interestingly, the Comics Code did not impose in its guidelines a similar standard for the quality of the images presented in comics. This in turn suggests that the narrative quality of a comics piece has been linked, even within the industry, to the realm of the literary more so than to the artistic. The "good grammar” enforced by the Comics Code is subject to rules established by media that treat image as illustration and not foundational to the narrative. Asserting the importance of textual grammar on the medium ensures the supplemental role of the image, and suggests that meaning is carried primarily by the text. The image, when structured around "textual” grammar, is meant not to impede meaning and any instance where the image stands in contrast to the text would be considered an issue of function, as the image fails to illustrate the words on the page.

Comics in their format have a multitude of conventions and styles that are as unique as the narrative within them. In reading comic formats critics like Wertham condemned that the reader was forced to adapt their understanding of how text functions based on the creator's individual narratological style instead of a uniform method. In turn, the unique form of a comic 
can be perceived as disruptive when trying to apply existing formal reading tendencies for textbased narrative. Wertham's is the clearest attack on the inclusion of the image in literature, as he states that the inclusion of images "is precisely one of the points where comic books are so harmful. They retard or even interfere with reading. ... comic-book reading is an inadequate experience” (Wertham 126). The inference that the image interferes with the reading of a narrative suggests that the image does not in itself perform any narrative function. However, it can also be said that the inclusion of text in a comic narrative can interfere just as much with reading comprehension and narrative flow. A variety of examples of how text can be imposed on comics’ narrative function is provided in Postema’s book. Postema makes a comparison between the different ways that comics have historically presented text, making use of Fletcher Hanks's I Shall Destroy All Civilized Planets! and of Spider-man publications by Stan Lee and Steve Ditko. Postema indicates in her breakdown of Hanks's work that the image is rendered redundant by the text. Critics of the medium seize on examples like The Super Wizard Stardust as a problem with the comics medium, in that it provides an alternative to reading, which renders the need to comprehend the written narrative in its entirety moot. In addition, the prose of narratives like The Super Wizard Stardust encourages the idea that the addition of image augments or promotes substandard prose. Yet as indicated by Postema, Hanks’s work does not demonstrate the power of image in conjunction with text but instead the sublimation of the image to text; the lack of narrative ability in Hanks’s artwork "illustrates that an excess of text, verbal overdetermination, also affects signification in comics. It can hamper the normal flow of the sequence, interrupting the function of the gap between panels” (Postema 90). The inclusion of the text-heavy dialogue boxes in panelling ruins the flow of the actual narrative; the information would be better conveyed without the image as it adds little to the understanding of the narrative. 
The word, in this case, is being used to make up for the artist's lack of ability to convey simple elements of the narrative. Even the structure of the boxes would be better suited for a more traditional literary format, as:

The flow of the captions across the page is structured like a series of sentences, or even a series of phrases forming a single sentence. Each phrase is accompanied by a picture, so that every panel illustrates a part of the sentence. The action is broken up according to sentence structure rather than according to the rhythm of the action or arc of events, with the results that the panels do not achieve flow as a visual sequence. (Postema 93) The plot of the comic can still be followed, as a reader defaults to a "word specific" format (McCloud 153), however important attributes of the narrative are lost. Another factor of how the visual in Stardust fails to add to the format is in how neutral the reactions of the characters and environment are to the extreme elements described in the prose. The characters' faces remain remarkably undynamic, offering no additional information that might convey the characters' feelings, anxieties, or the impacts on them of the goings on in their surroundings. It can be argued, based on Postema's breakdown, that Hanks' work does not, therefore, demonstrate the basic level of utilization of the image, as it acts as little more than illustration. The fact that Hanks' work was and continues to be considered a comic confuses the discourse, as regardless of his artistic ability the prose only works if it is held to the standards of literary design and formatting; i.e. analysis is necessary which simultaneously considers both text and image as equivalent contributions to the narrative. 


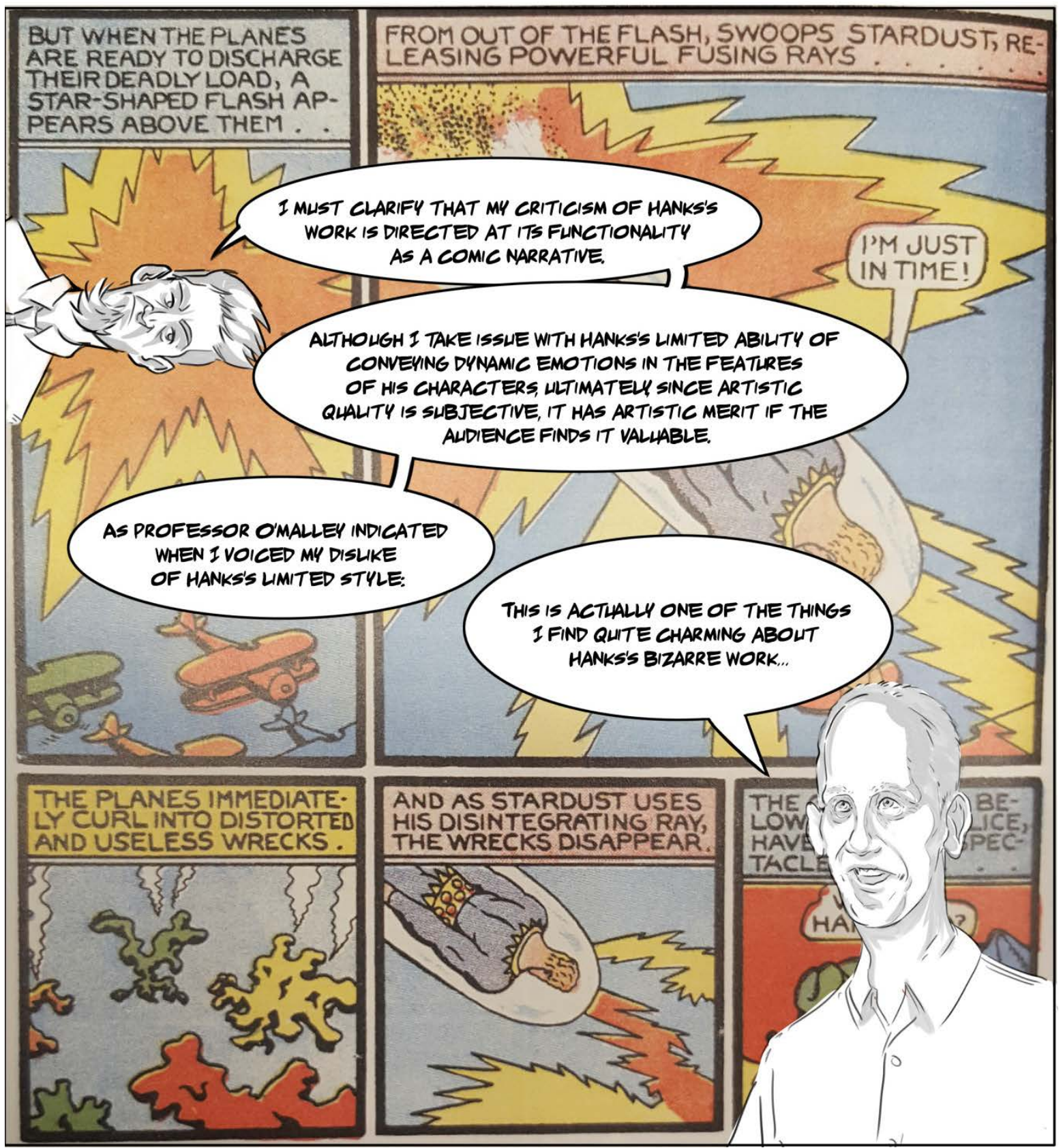


WHEN DISCUSSING IMAGE AND TEXT IT IS APPARENT THAT THE APPROACH TO COMICS IN THE PAST HAS LEFT A LASTING IMPRESSION ON READERS WHEN ASSESSING THE ROLE OF THE IMAGE. BARBRA POSTEMA MAKES NOTE OF APARTICULAR STYLE THAT WAS COMMON IN GOLDEN AGE COMICS, WHICH PLACED THE TEXT AS PARAMOLNT AND THE IMAGE AS LITTLE MORE THAN AN ILLLSTRATION THAT WENT ALONG WITH THETEXT. THIS STYLE GAVE THE IMAGE AN IMPRESSION OF BENG SOMETHING SLPERFLUOUS AND REDUCED THE IMAGE TO LITTLE MORE THAN A VISLAL DISTRACTION TO DRAW THE EYE. THE FOLLOWING SECTION IS AN EXAMPLE OF THEFORMAT USED IN THE GOLDEN AGE OF COMICS.

MICHAEL RETRIEVES THE COMIC PAGES HE NEEDS FROM HIS BOOK BAG!

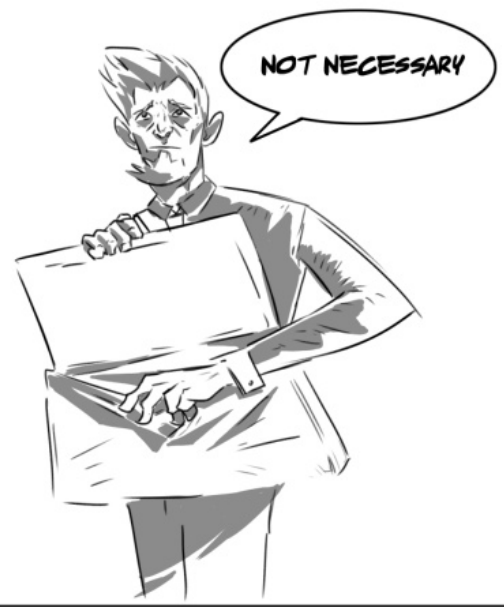

HESTARES AT THEM INTENTLY HOPING THEY WILL ADD ADDITIONAL MEANING!

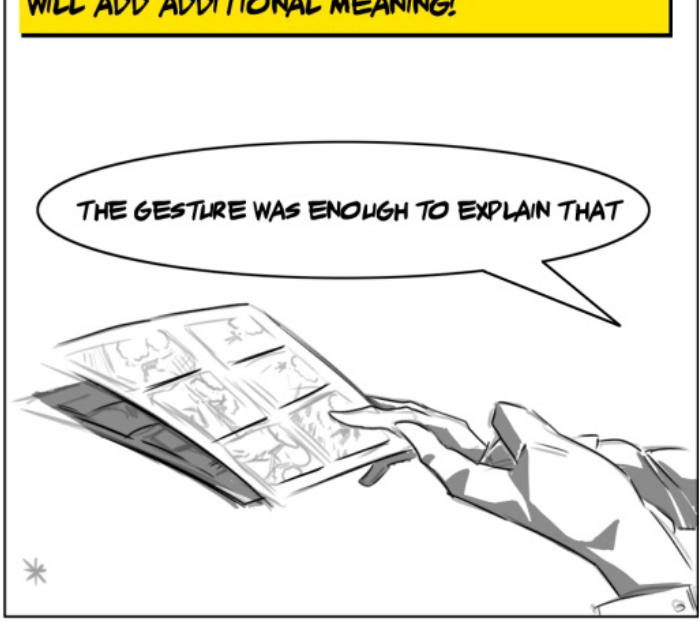

IN HIS HANDS HE HOLDS THE PAGES HE KNOWS TO BE IMPORTANT TO HIS ARGLMENT!
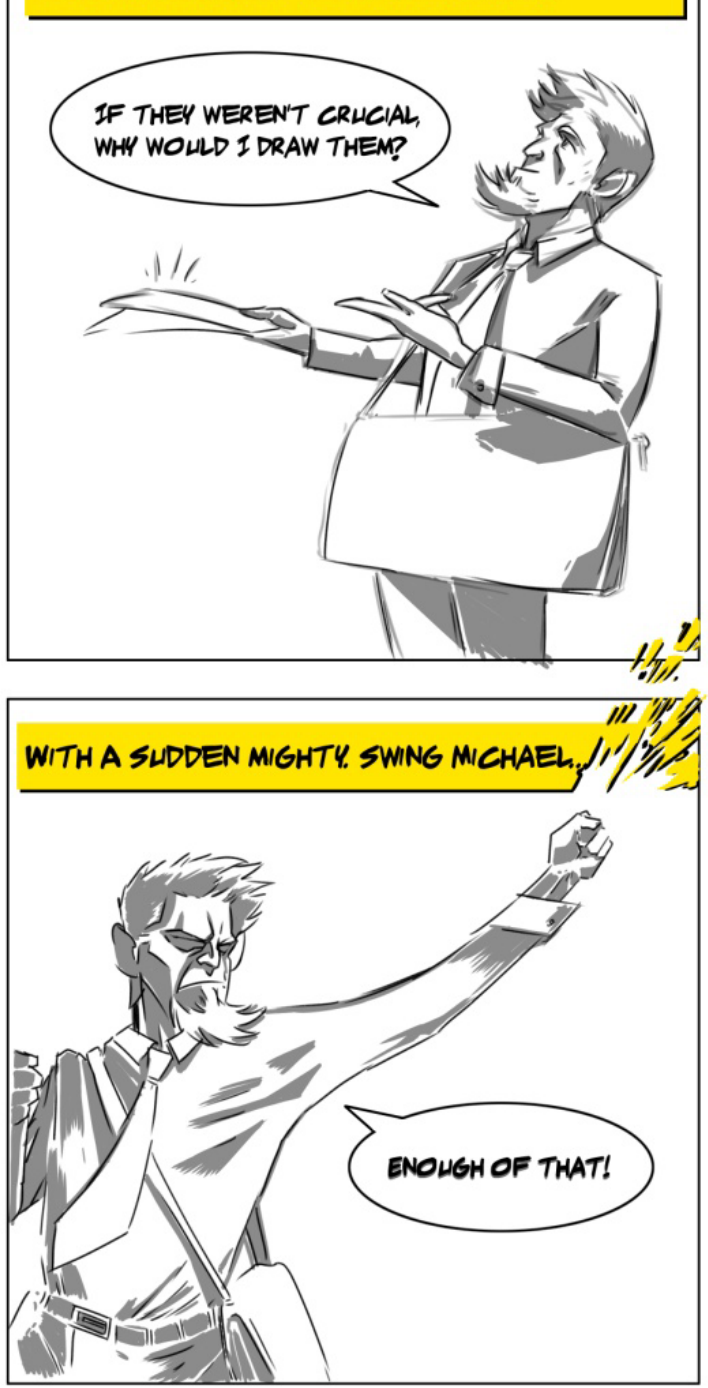
Seravalle 45
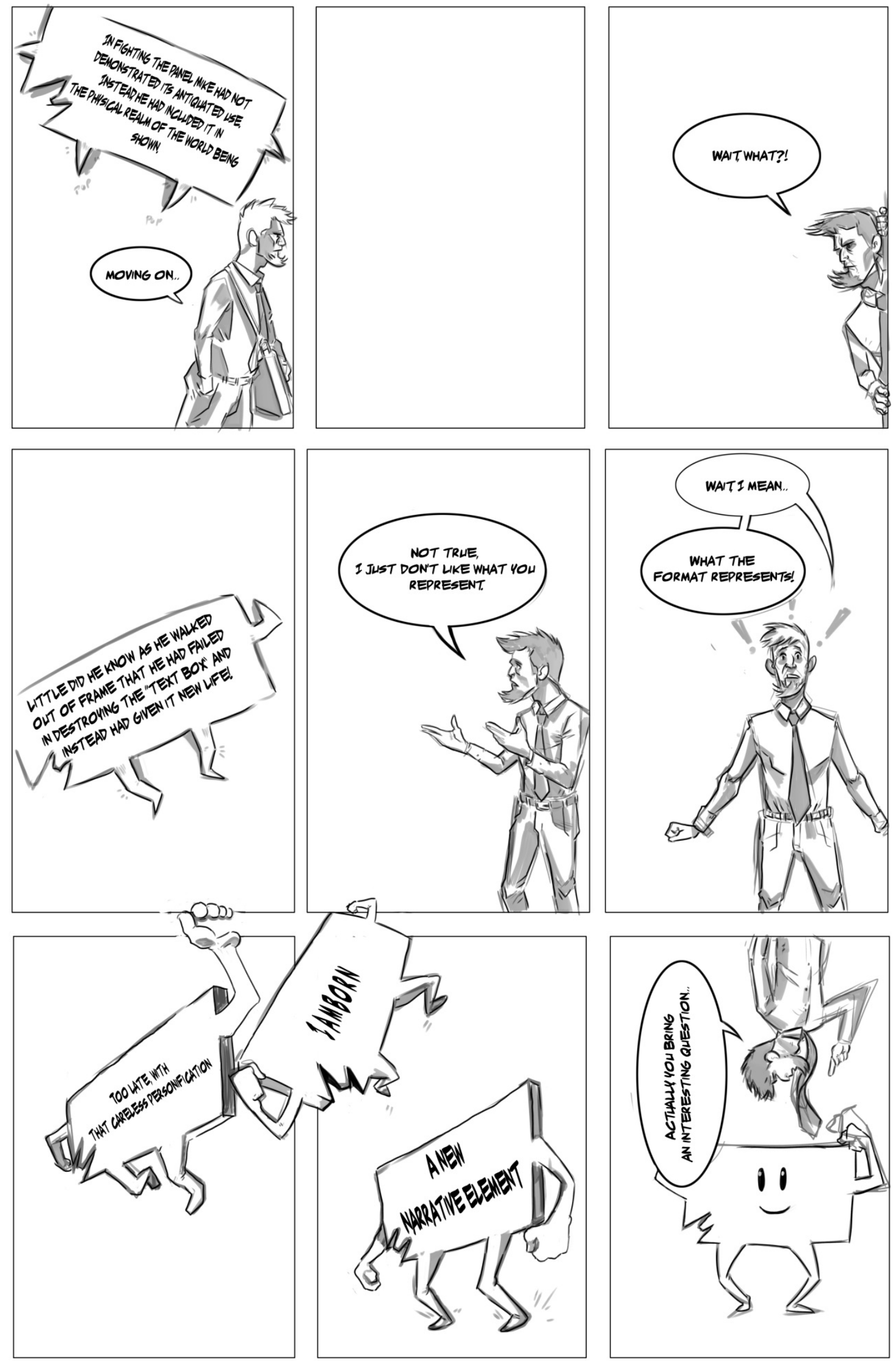

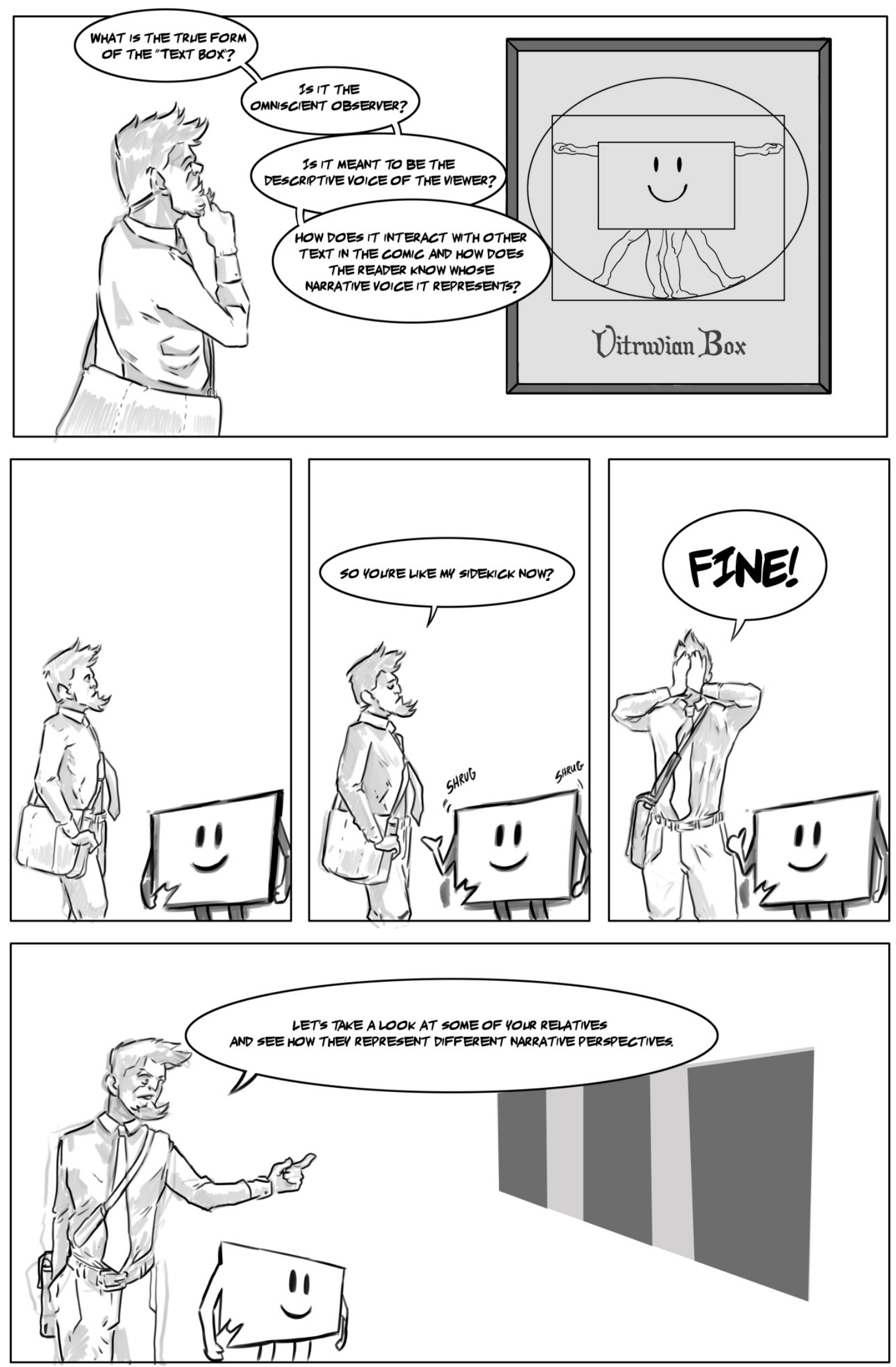


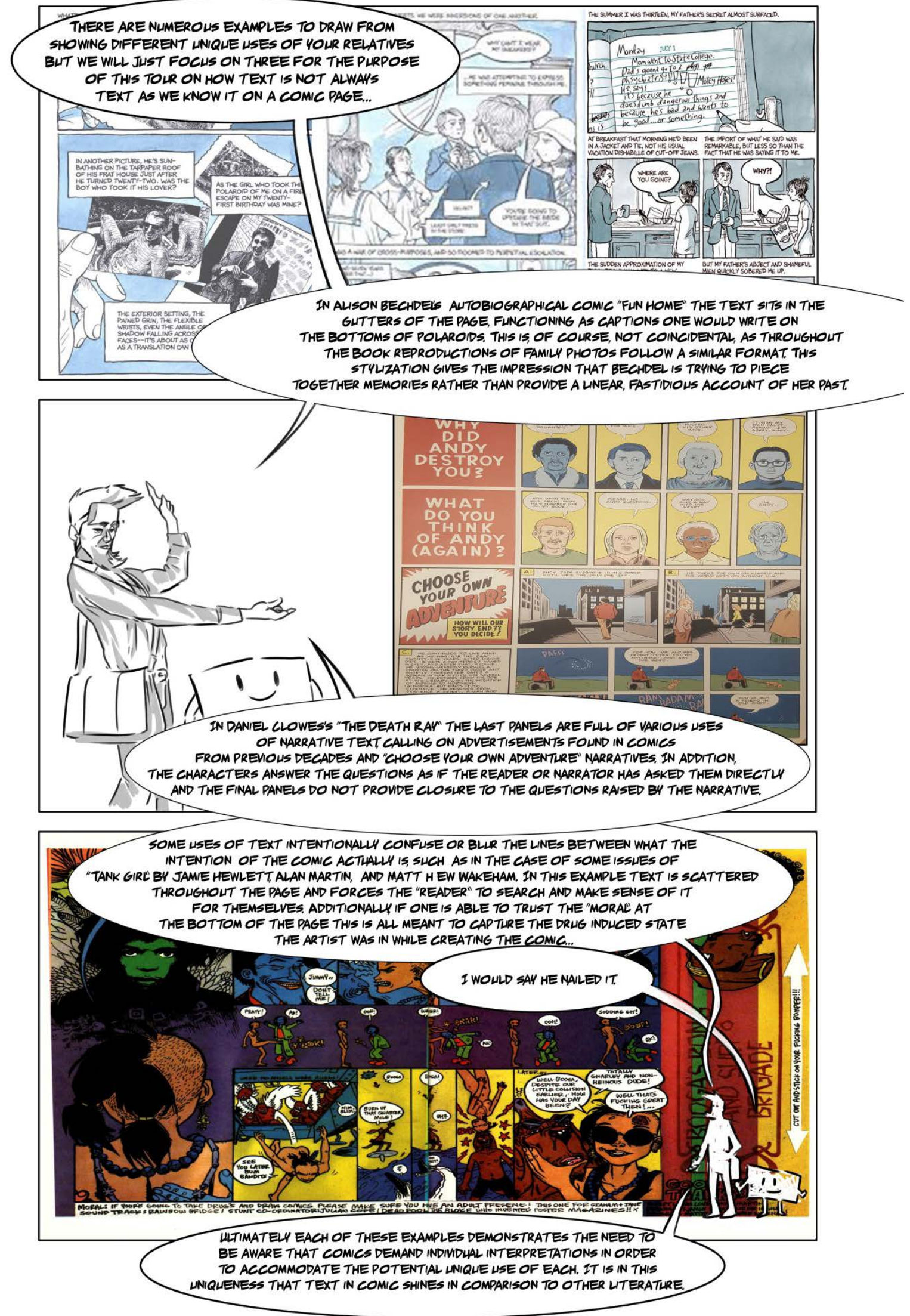


As the comic pages above illustrate, the text in comics does not usually represent traditional text narrative form. The creators and collaborators who construct comics narrative through various techniques bend text to act in ways that demand the consideration of the visual as part of their narrative function. The visual representation of the text can therefore at times be considered a form of image. Subjugating the image to an illustrative role and treating textual narrative as paramount, in turn, limits the text to the standards of traditional literary formats. How text is presented on a page of a comic can have drastic effects on the reader's interpretation of the narrative. ${ }^{1}$ In effect, the tendency to subjugate the image also inadvertently subjugates the text. As Postema points out in her analysis of Lee and Ditko’s work on Spider-man in the 1950s-60s, the narrative writing in comics shifted to an almost conversational format that saw the hero sometimes breaking the fourth wall in addressing what he was doing and the reasons for his actions. In a way, the character was having a conversation with the text box that was narrating the events on the page. Interestingly, this development represented a truer attempt at incorporating image and text in the presentation of narrative as the protagonist reflected on his actions without having to narrate them for clarity. Lee and Ditko's work with Spider-man was motivated by the need to conform to the standards outlined by the Comics Code to encourage literacy. Through this they contributed to the development of a unique comic narrative style that adhered to the standards of traditional text narration but also evolved it for the medium. The combination of the format, both within and outside of the text box, is suggested by Groensteen who states that: “the 'explicit traces of narrator' identified in literary works were necessarily linguistic traces” (82-83). This expands further the idea that the way in which linguistic presentation is handled in comics can have drastic effects simply in the acknowledgement of the visual use of text. "The difficulty of elaborating a narratology for comic art arises out of its 
poly-semiotic nature. It combines text and image in varying proportions. It is essential to start with the assumption that both play a full part in the narrative process” (Groensteen 82). The issue critically is where to limit the analysis when looking at a comic format; in Groensteen's words: "all that needs to be said is that graphic monstration is never neutral, given that any drawing is necessarily signed and marked by a considerable degree of uniqueness” (85). This uniqueness suggests a need to move away from the current label of the medium as "literature" and the ascribed methods of analysis which favour the written word, as they do not accommodate the variety of analysis that the medium demands.

As stated earlier, both in the above analysis of Nodelman's comparison of comics to picture books and Wertham's attacks, comics demand concentration due to their complexity and, as medium, demand a different approach to the traditional comparisons to literary forms of media. Part of the frustration with the medium is explained by Bourdieu: "A beholder who lacks the specific code feels lost in a chaos of sounds and rhythms, colours and lines, without rhyme or reason. Not having learnt to adopt the adequate disposition, he stops short at what Erwin Panofsky calls the 'sensible properties'” (Bourdieu 2). At times the reader of a comic must break from the established flow of traditional textual narrative, as indicated by Charles Hatfield, who says that, "[f]rom a reader's point of view, comics would seem to be radically fragmented and unstable"; yet, later in the same article, Hatfield reveals that "this is their great strength: comic art is composed of several kinds of tension, in which various ways of reading - various interpretive options and potentialities - must be played against each other” (Hatfield 36). When all elements of the narrative and format are considered, i.e. image, text, and their respective positions on the page, more complex and dynamic possibilities are revealed to the comics' audience, ones that may not be possible in other media. 
The way we take in literature can be compared to the development of the "eye" which takes in the information and derives meaning from it.

"The 'eye' is a product of history reproduced by education.

This is true of the mode of artistic perception now accepted as legitimate, that is, the aesthetic disposition,

the capacity to consider in and for themselves, as form rather than function, not only the works designated for such apprehension, i.e., legitimate works of art, but everything in the world, including cultural objects which are not yet consecrated - such as, at one time, primitive arts... (Bourdieu 3)

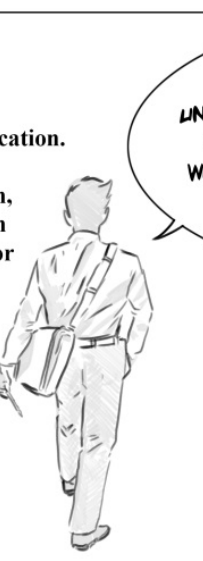

BLT IN THE CASE OF COMICS THERE IS A MLLTITLDE OF "EYES" REQUIRED TO FULLY UNDERSTAND THE FLNCTIONS OF EACH ELEMENT OF THE COMICS NARRATIVE... SO IN KEEPING WITH THE FLNCTION OF THE COMICS NARRATIVE

I WOULD LIKE TO CLOSE OUT WITH AN OBSERVATION OF HOW THE
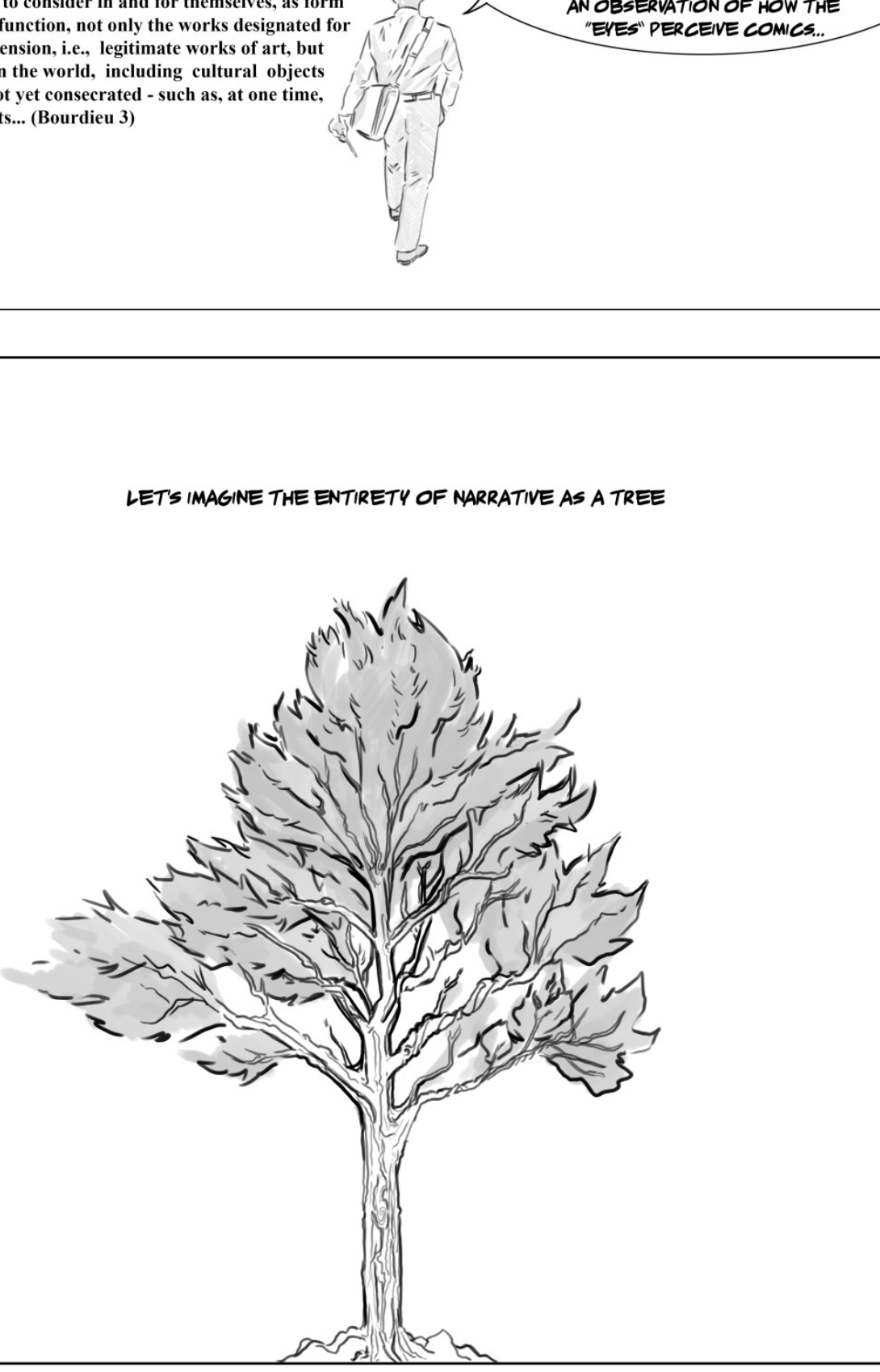

EACH PART OF THE TREE REPRESENTS DIFFERENT ELEMENTS OF THE NARRATIVE: CHARACTER, SETTING, MOOD..
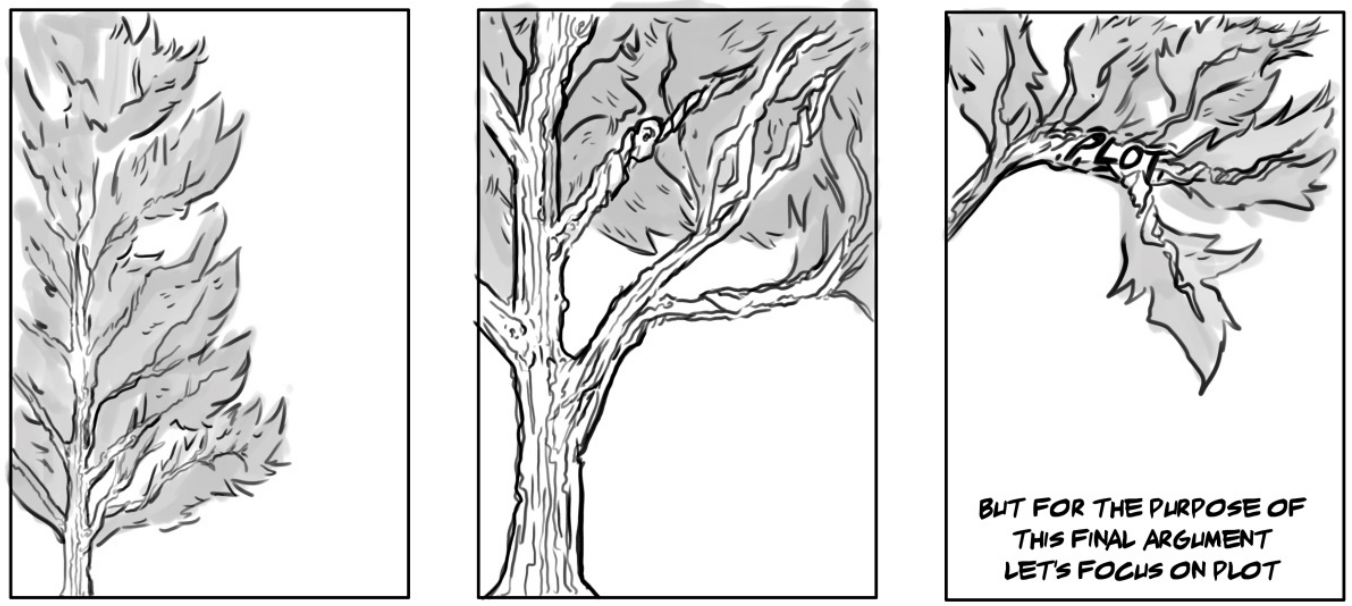


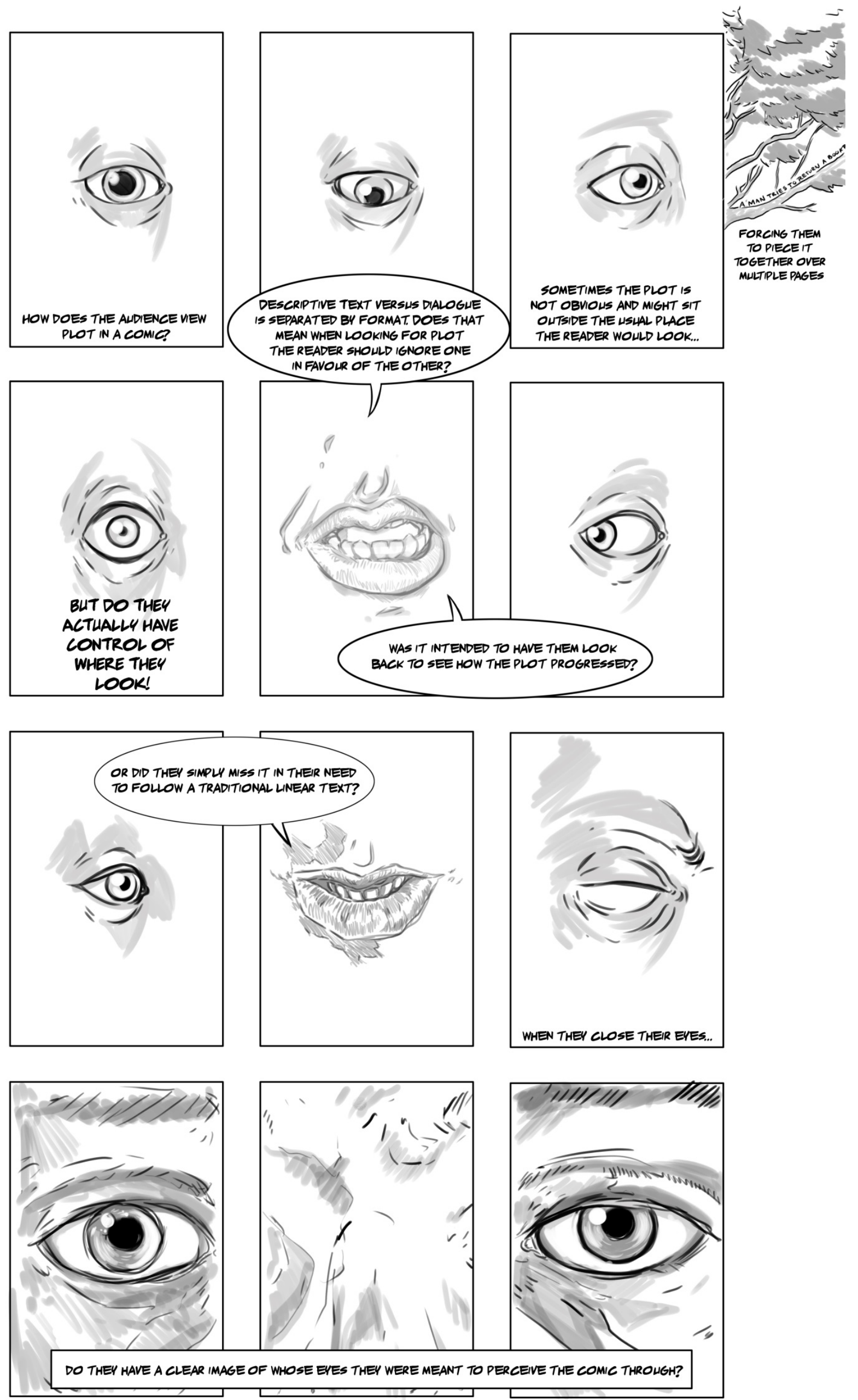



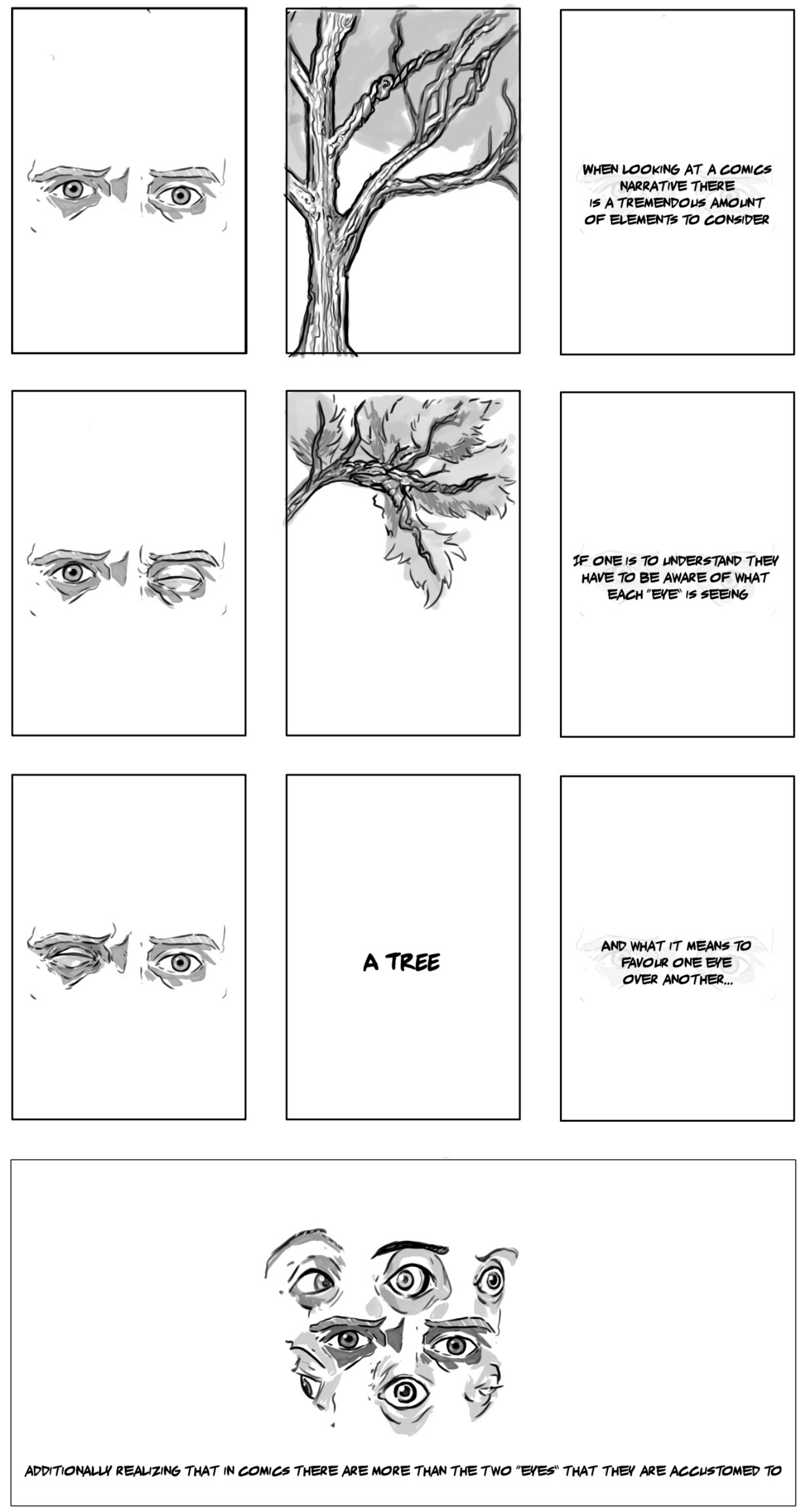

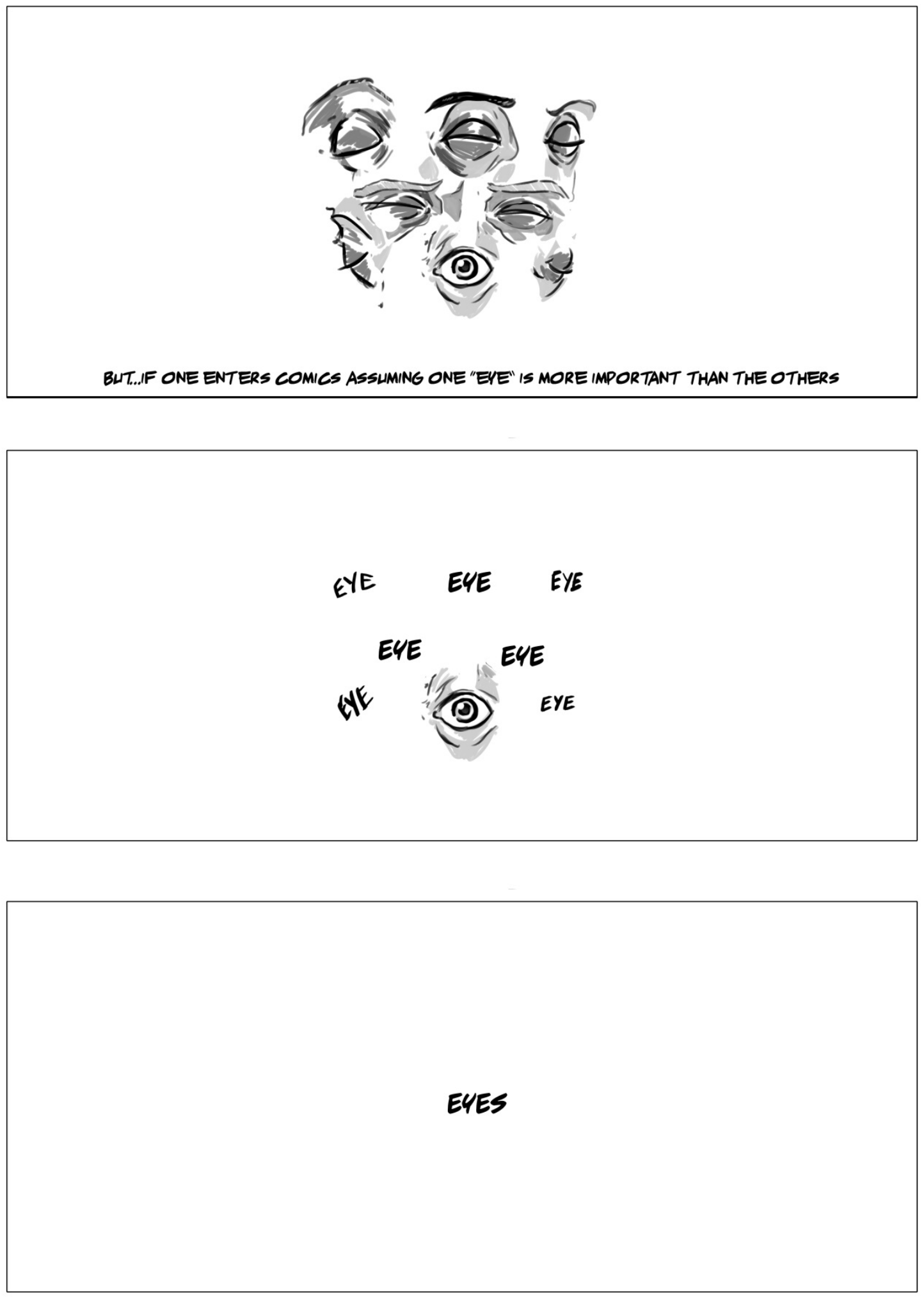


\section{Notes}

${ }^{1}$ There are certainly similar examples of meaning being carried by typographic effects in strictly

literary media, examples being form poetry and certain novels, such as parts of Laurence Sterne’s The Life and Opinions of Tristram Shandy, Gentleman. 


\section{Works Cited}

Beaty, Bart. Comics vs Art. Toronto UP, 2012.

---. Fredric Wertham and the Critique of Mass Culture : A Re-Examination of the Critic Whose Congressional Testimony Sparked the Comics Code. Mississippi UP, 2005.

Bechdel, Alison. Fun Home: A Family Tragicomic. First Mariner Books Edition, 2007.

Bourdieu, Pierre. Distinction. A Social Critique of the Judgement of Taste. Translated by Richard Price, Harvard UP, 1979.

Clowes, Daniel. The Death-Ray. Drawn and Quarterly, 2004.

Gabilliet, Jean-Paul. Of comics and men: a cultural history of American comic books. Translated by Bart Beaty and Nick Nguyen, Mississippi UP, 2010.

Gaiman, Neil. Sandman, The: \#1 Preludes \& Nocturnes. With an introduction by Karen Berger, DC Comics, 1991.

Groensteen, Thierry. Comics and Narration. Translated by Ann Miller, Mississippi UP, 2013.

---. The System of Comics. Translated by Bart Beaty and Nick Nguyen, Mississippi UP, 2007.

Hatfield, Charles. Alternative comics: an emerging literature. Mississippi UP, 2005.

““I Could Relate Very Closely To Your Alienation’: A Conversation Between Daniel Clowes and Jonathan Lethem.” The Best American Comics Criticism. Edited by Ben Shwartz, Fantagraphics Books, 2010, pp. 331-342.

Hewlett, Jamie and Alan Martin. Tank Girl 2. Titan Publishing Group Ltd., 2002.

Kidder, Orion U. Telling stories about storytelling: The metacomics of Alan Moore, Neil Gaiman, and Warren Ellis. Dissertation, Alberta UP, 2010.

McCloud, Scott. Understanding comics: the invisible art. HarperPerennial, 1994.

Miodrag, Hannah. Comics and Language: Reimagining Critical Discourse on the Form. Mississippi UP, 2013. 
Nodelman, Perry. "Picture Book Guy Looks at Comics: Structural Differences in Two Kinds of Visual Narrative.” Children's Literature Association Quarterly, vol. 37, no. 4, 2012, pp. 436-444.

Nyberg, Amy Kiste. Seal of Approval: The History of the Comics Code (Studies in Popular Culture). Mississippi UP, 1998. Kindle Ebooks, https://www.amazon.com/SealApproval-History-Studies-Popular-ebook/dp/B001M0O35A/ref=sr_1_1?s=digitaltext\&ie=UTF8\&qid=1533586218\&sr=11\&keywords=Seal+of+Approval\%3A+The+History+of+the+Comics+Code+\%28Studies +in+Popular+Culture\%29.

Phoenix, Charles M. Classroom Comics: A Five-Part Narrative Recounting a Teacher Action Research Study Using Comics to Teach Academic Vocabulary in the Middle Grades. Dissertation, Missouri - Saint Louis UP, 2016, AAP 10153599.

Postema, Barbara. Narrative Structure in Comics: Making Sense of Fragments. RIT Press, 2013. Spiegelman, Art. Interview by W.J.T. Mitchell. Public Conversation: What the \%\$\#! Happened to Comics? 19 May. 2012, https://www.journals.uchicago.edu/doi/10.1086/677327. Accessed 23 May. 2018.

Tilly, Carol L. "Seducing the Innocent: Fredric Wertham and the Falsifications That Helped Condemn Comics.” Information \& Culture, vol. 47, no. 4, 2012, pp. 383-413.

Wertham, Fredric. Seduction of the Innocent. Rinehart \& Company, 1954. 
Seravalle 57

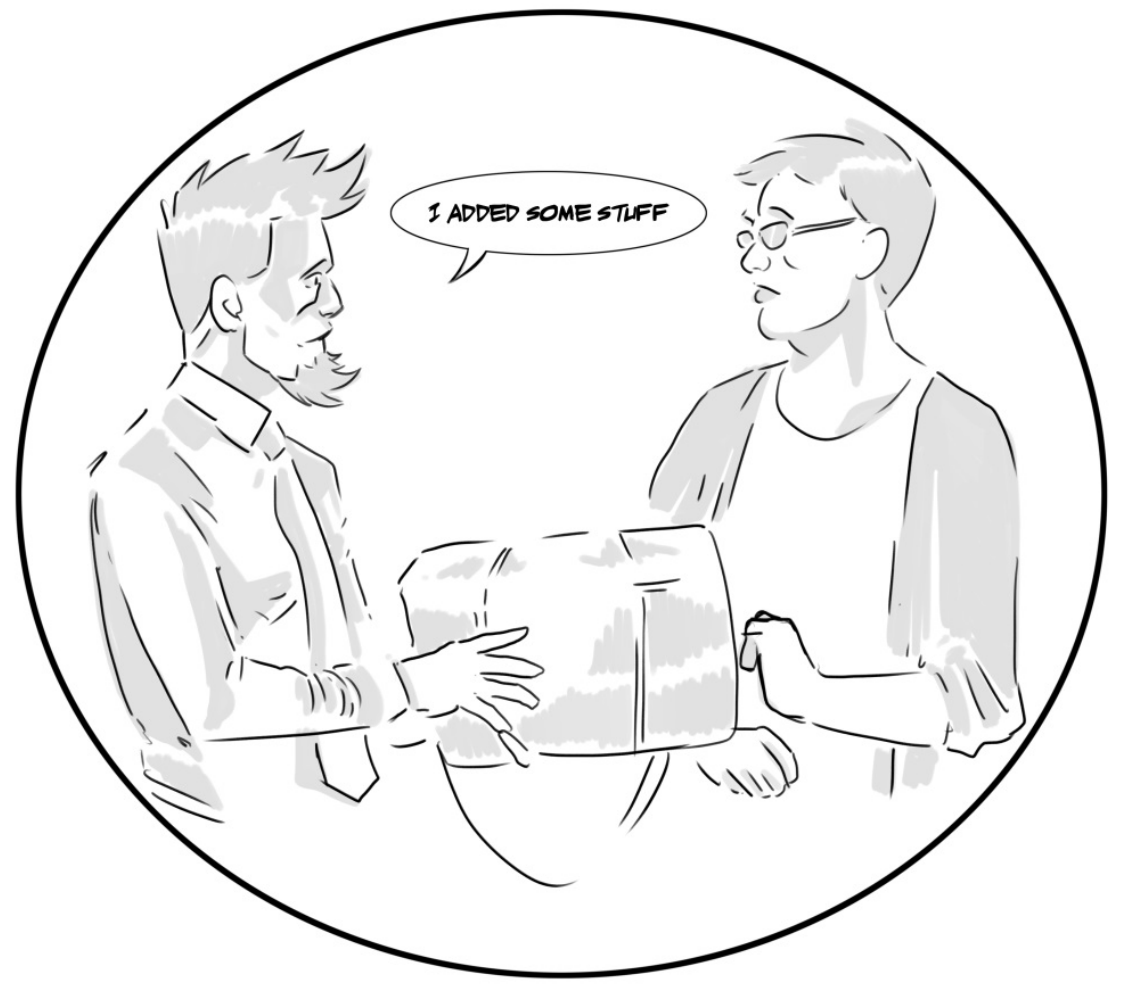

